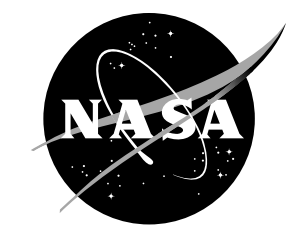

\title{
Modeling the Deterioration of Engine and Low Pressure Compressor Performance During a Roll Back Event Due to Ice Accretion
}

Joseph P. Veres, Philip C.E. Jorgenson, and Scott M. Jones Glenn Research Center, Cleveland, Ohio 


\section{NASA STI Program . . . in Profile}

Since its founding, NASA has been dedicated to the advancement of aeronautics and space science. The NASA Scientific and Technical Information (STI) program plays a key part in helping NASA maintain this important role.

The NASA STI Program operates under the auspices of the Agency Chief Information Officer. It collects, organizes, provides for archiving, and disseminates NASA's STI. The NASA STI program provides access to the NASA Aeronautics and Space Database and its public interface, the NASA Technical Reports Server, thus providing one of the largest collections of aeronautical and space science STI in the world. Results are published in both non-NASA channels and by NASA in the NASA STI Report Series, which includes the following report types:

- TECHNICAL PUBLICATION. Reports of completed research or a major significant phase of research that present the results of NASA programs and include extensive data or theoretical analysis. Includes compilations of significant scientific and technical data and information deemed to be of continuing reference value. NASA counterpart of peer-reviewed formal professional papers but has less stringent limitations on manuscript length and extent of graphic presentations.

- TECHNICAL MEMORANDUM. Scientific and technical findings that are preliminary or of specialized interest, e.g., quick release reports, working papers, and bibliographies that contain minimal annotation. Does not contain extensive analysis.

- CONTRACTOR REPORT. Scientific and technical findings by NASA-sponsored contractors and grantees.
- CONFERENCE PUBLICATION. Collected papers from scientific and technical conferences, symposia, seminars, or other meetings sponsored or cosponsored by NASA.

- SPECIAL PUBLICATION. Scientific, technical, or historical information from NASA programs, projects, and missions, often concerned with subjects having substantial public interest.

- TECHNICAL TRANSLATION. Englishlanguage translations of foreign scientific and technical material pertinent to NASA's mission.

Specialized services also include creating custom thesauri, building customized databases, organizing and publishing research results.

For more information about the NASA STI program, see the following:

- Access the NASA STI program home page at http://www.sti.nasa.gov

- E-mail your question to help@sti.nasa.gov

- Fax your question to the NASA STI Information Desk at 443-757-5803

- Phone the NASA STI Information Desk at 443-757-5802

- Write to: STI Information Desk NASA Center for AeroSpace Information 7115 Standard Drive Hanover, MD 21076-1320 


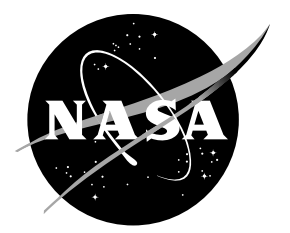

\section{Modeling the Deterioration of Engine and Low Pressure Compressor Performance During a Roll Back Event Due to Ice Accretion}

Joseph P. Veres, Philip C.E. Jorgenson, and Scott M. Jones Glenn Research Center, Cleveland, Ohio

Prepared for the 50th Joint Propulsion Conference cosponsored by AIAA, ASME, SAE, and ASEE Cleveland, Ohio, July 28-30, 2014

National Aeronautics and

Space Administration

Glenn Research Center Cleveland, Ohio 44135 


\section{Acknowledgments}

This work is supported by the Atmospheric Environment Safety Technology Project (AEST) in the NASAAviation Safety Program, and is in response to the Engine Icing Technical Challenge. We would like to thank Dr. Renato Colantonio, manager of the NASA Atmospheric Environment Safety Technologies (AEST) project, under the Aviation Safety Program (ASP) for supporting this work. We would also like to acknowledge Dr. Michael Oliver, Dr. Judith Foss Van Zante, Timothy Bencic, Amy Fagan, Christopher Lynch, Bryan Rosine, Tom Griffin, Queito Thomas, Jonathan Paul Kirkegaard, Dennis Dicki, Paul Lizanich, Steve Pesek, Pamela Poljak, Kent A. Smith, and the rest of the PSL technicians and engineers that supported the test and facility development at NASA Glenn Research Center for providing the excellent test data for this engine in the unique altitude test facility with spray bars that successfully simulated ice ingestion testing. We also acknowledge the help and guidance we received in the area of icing from Dr. Peter Struk, Dr. William B. Wright (Vantage Partners, LLC) for guidance in providing the MELT code, and Dr. Jen-Ching Tsao (Ohio Aerospace Institute) for his insights and analyses.

Level of Review: This material has been technically reviewed by technical management.

Available from

NASA Center for Aerospace Information 7115 Standard Drive

Hanover, MD 21076-1320
National Technical Information Service 5301 Shawnee Road Alexandria, VA 22312 


\title{
Modeling the Deterioration of Engine and Low Pressure Compressor Performance During a Roll Back Event Due to Ice Accretion
}

\author{
Joseph P. Veres, Philip C.E. Jorgenson, and Scott M. Jones \\ National Aeronautics and Space Administration \\ Glenn Research Center \\ Cleveland, Ohio 44135
}

\begin{abstract}
The main focus of this study is to apply a computational tool for the flow analysis of the engine that has been tested with ice crystal ingestion in the Propulsion Systems Laboratory (PSL) of NASA Glenn Research Center. A data point was selected for analysis during which the engine experienced a full roll back event due to the ice accretion on the blades and flow path of the low pressure compressor. The computational tool consists of the Numerical Propulsion System Simulation (NPSS) engine system thermodynamic cycle code, and an Euler-based compressor flow analysis code, that has an ice particle melt estimation code with the capability of determining the rate of sublimation, melting, and evaporation through the compressor blade rows. Decreasing the performance characteristics of the low pressure compressor (LPC) within the NPSS cycle analysis resulted in matching the overall engine performance parameters measured during testing at data points in short time intervals through the progression of the roll back event. Detailed analysis of the fan-core and LPC with the compressor flow analysis code simulated the effects of ice accretion by increasing the aerodynamic blockage and pressure losses through the low pressure compressor until achieving a match with the NPSS cycle analysis results, at each scan. With the additional blockages and losses in the LPC, the compressor flow analysis code results were able to numerically reproduce the performance that was determined by the NPSS cycle analysis, which was in agreement with the PSL engine test data. The compressor flow analysis indicated that the blockage due to ice accretion in the LPC exit guide vane stators caused the exit guide vane (EGV) to be nearly choked, significantly reducing the air flow rate into the core. This caused the LPC to eventually be in stall due to increasing levels of diffusion in the rotors and high incidence angles in the inlet guide vane (IGV) and EGV stators. The flow analysis indicating compressor stall is substantiated by the video images of the IGV taken during the PSL test, which showed water on the surface of the IGV flowing upstream out of the engine, indicating flow reversal, which is characteristic of a stalled compressor.
\end{abstract}

\section{Introduction}

The purpose of this study is to utilize a computational tool to improve the understanding of the low pressure compressor and engine performance during an engine roll back event caused by ice accretion. Ice crystals ingested into the engines during the operation of an aircraft at high altitudes in high ice water content (HIWC) environments can result in ice accretion in the low pressure compression system. As ice crystals are ingested into the fan and low pressure compression system, where the air static temperature typically increases, a portion of the ice crystals melt due to the warmer air. This allows the ice-water mixture to stick (accrete) when they impact the metal surfaces of the compressor components. The resulting accretion causes a blockage on stationary components such as the stator vanes, and subsequently results in the deterioration in performance of the compressor and the ultimate reduction of engine thrust. There have been numerous reported engine icing events (Refs. 1 and 2) that have occurred on commercial airlines (Fig. 1). The total number of engine icing events per year that were attributed to high ice water clouds appears to be increasing since 2002 (Ref. 3). 


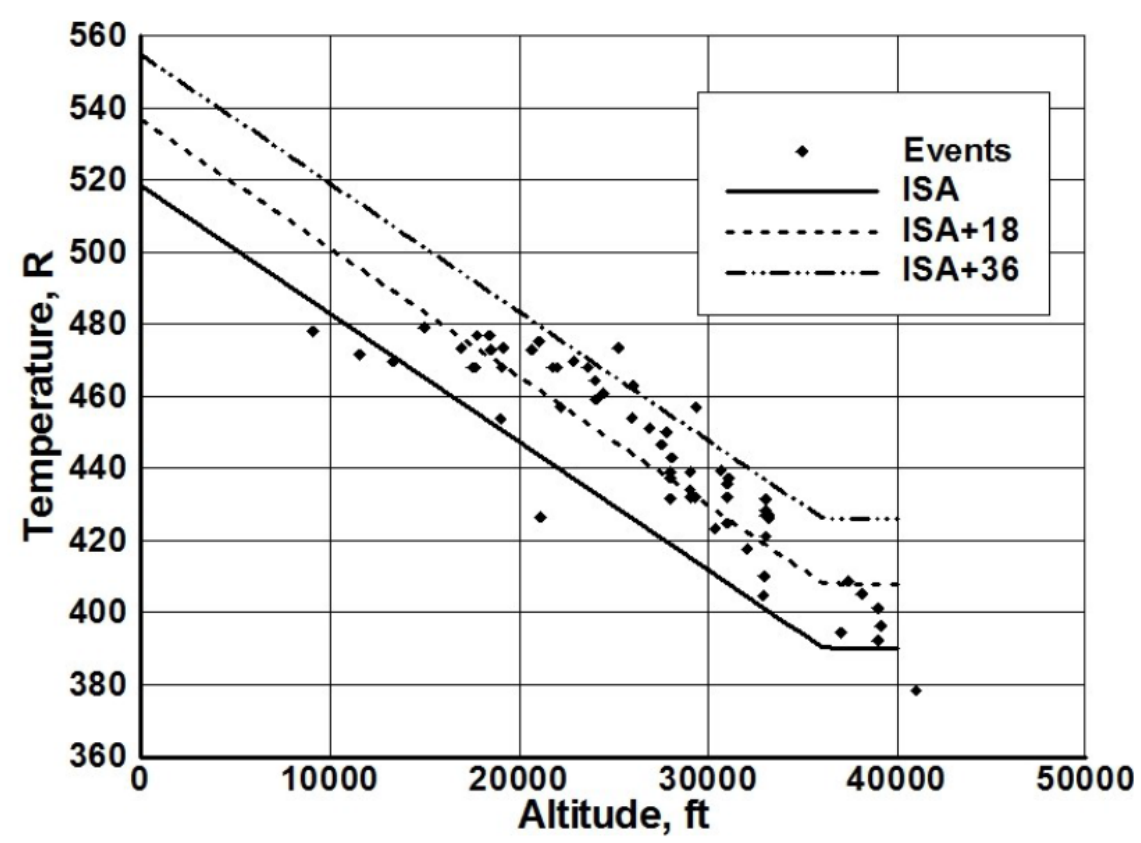

Figure 1.-Reported engine icing events. The engine events occurred at altitudes between 10 and $40 \mathrm{~K} \mathrm{ft}$ and at temperatures between International Standard Atmosphere (ISA) and +36 R.

In this study we analyze a turbofan engine that was tested in the Propulsion Systems Laboratory (PSL) at NASA Glenn Research Center with ice crystal ingestion at a simulated high altitude. The test point (data point 940) that was selected for analysis in this study was at an operating condition which resulted in an uncommanded loss of thrust, referred to as an engine roll back. This data point represented an operating point in the aircraft flight trajectory where this same engine experienced engine roll back during flight through a convective cloud which was suspected to contain ice crystals.

\section{Engine Modeling Tool}

The computational tool that was utilized in this study has the capability to analyze a turbine engine that is flying through an ice cloud along a flight trajectory, and can evaluate the risk of accretion, as well as to estimate the engine performance degradation due to accretion. The tool is comprised of the Numerical Propulsion System Simulation (NPSS) (Ref. 4) as the engine system thermodynamic cycle code, coupled with a compressor flow analysis code COMDES (Ref. 5) with a fluid properties package, and an ice particle melt code. The NPSS code provides the overall component-level performance and flow conditions of pressures and temperatures. In the mixed fidelity analysis COMDES provides the bladerow-by-blade-row aerodynamics, as well as the overall fan-core and LPC performance, thereby replacing the characteristic maps typically used by NPSS. This work leverages from the previous efforts of tool development and parametric studies of the effects of blockage due to ice accretion on engine and compressor performance reported in References 6 to 9 . 


\section{Engine Roll Back Data and Analysis}

\section{Full Engine Roll Back: PSL Test Data Point 940}

During the testing with the ice cloud on, the engine experienced several engine roll back events (Refs. 10 and 11). For this study, the full engine roll back Escort data point 940 was selected for detailed analysis. The engine data recorded in the PSL Escort system was comprised of: air flow, fan speed (N1), core speed (N2), fuel flow, HPC exit total pressure (Pt3) and temperatures (Tt3a, Tt3b), and high pressure turbine exit total temperature ( $\mathrm{Tt} 45)$. Figure 2 illustrates the variation of these parameters (nondimensionalized), through the complete roll back of the engine. The ice cloud was turned on at scan number 12 . The scan rate of the data acquisition system is approximately one scan per second. The engine performance as indicated by the measured parameters change almost immediately after the ice cloud was initiated. Initially the fan speed increases, along with fuel flow. After scan 80 the fan speed starts to decrease, as the engine performance begins to deteriorate. The decay of the engine continues through scan number 300, with a steady uncommanded decrease of N1, Pt3, Tt3 and fuel flow rate. Eventually N2 reaches a control limit (near scan 310), where the engine rolls back abruptly to a stable sub-idle operating condition, as indicated by a rapid decay of $\mathrm{N} 1$ and $\mathrm{N} 2$. This operating condition continues until the ice cloud is turned off (at scan 321). Eventually the engine recovers after several additional minutes of operating in the sub-idle mode.

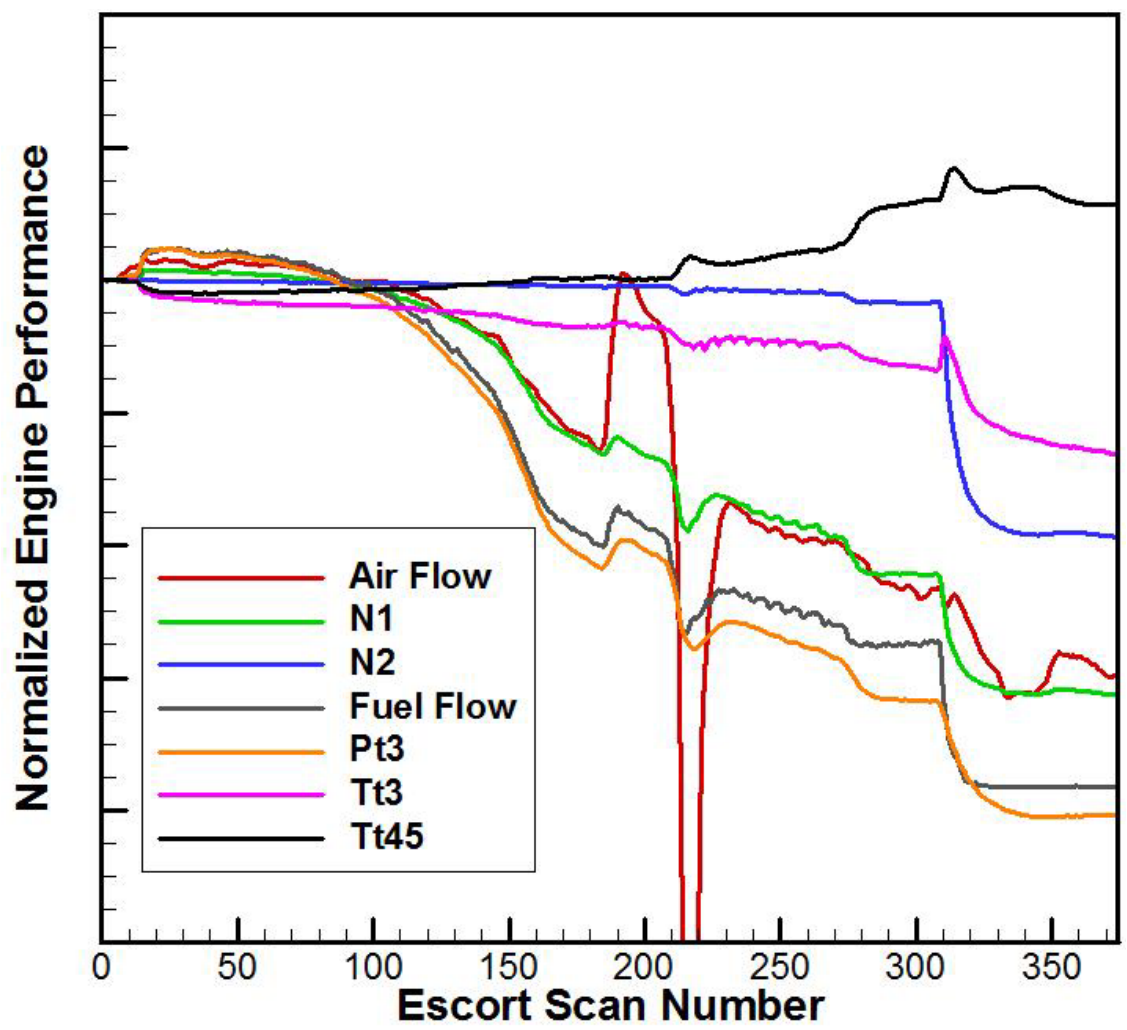

Figure 2.-Test data point 940 illustrating the variation of measured engine parameters with the ice cloud on and culminating in a full engine roll back event. 


\section{Engine System Model With the Numerical Propulsion System Simulation (NPSS) Code}

An NPSS model of the tested turbofan engine was created; a set of turbomachinery maps representative of the fan-tip, the fan-core and LPC booster, the high pressure compressor, the high pressure turbine, and the low pressure turbine were used as part of the nominal off-design performance modeling. Initially, an attempt was made to run the NPSS fully coupled to COMDES, as in the previous studies (Refs. 6 to 9). However, it was found that running these codes fully coupled did not result in a converged solution when high levels of aerodynamic blockage were added to the LPC stators. The reason for non-convergence could be attributed to a low operating line due to near choke conditions in the LPC exit guide vane stators. For this reason, the codes were run independently. First, NPSS was used to determine the performance degradations for the fan-core and LPC, and then COMDES was executed to determine the aerodynamic blockages and operating characteristics of the fan-core and LPC.

The NPSS model was altered in two significant ways to enable simulating the degraded engine performance that occurred during the engine roll back event caused by ice particle ingestion. The block diagram in Figure 3 illustrates the NPSS turbofan engine model and its components. First, the effect of ice accretion on the LPC structures was taken into account. This was modeled by using scalars (Fig. 3) to degrade the performance of the fan-core and LPC map; furthermore, an additional stagnation pressure drop was applied to the LPC exit duct. Second, the effect of heat transfer between the air and ice particles was also applied: upon inspection of the engine test data, it was noticed that there was an abrupt 2.5 percent drop (Fig. 4) in the HPC exit temperature (Tt3) $10 \mathrm{sec}$ after the ice cloud was initiated which, it is thought, could not have been caused by ice accretion in that short time interval. It was theorized that there must be another mechanism involved, mainly the extraction of enthalpy from the air by the ice crystal particles as they change state from being partially melted in the LPC to becoming high temperature vapor by the time they reach the HPC exit. While the change in engine operating conditions was clearly a transient effect, up until the point where engine operating limits were reached (about scan 310 ), these changes occurred gradually over a span of about $5 \mathrm{~min}$. Therefore it was assumed that running

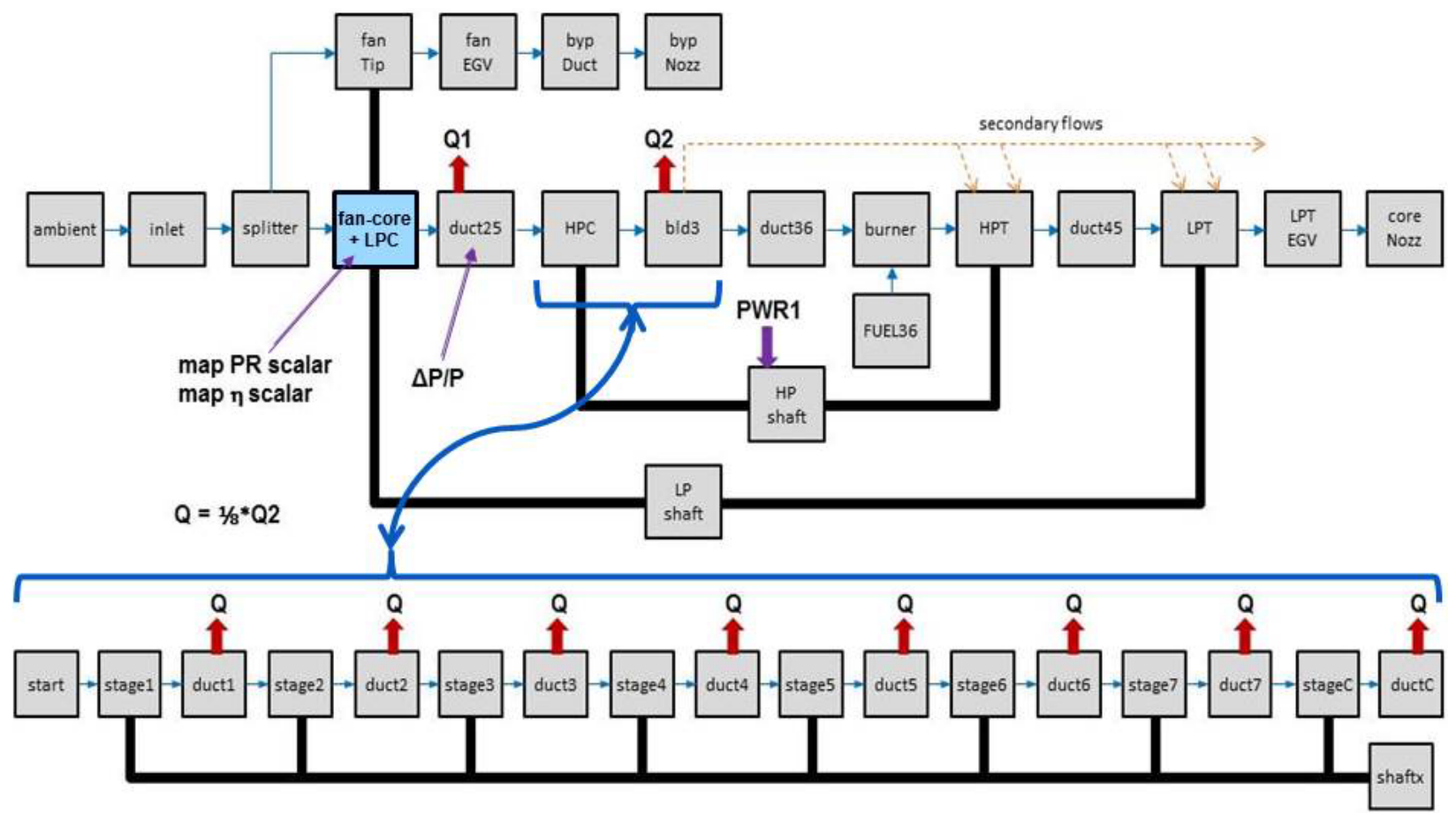

Figure 3.-The NPSS engine system model of the two spool turbofan engine. For the purpose of enthalpy exchange between the air and the ice particles, the HPC is divided into eight compressor stages. Note that the fan is split into the fan-tip and the fan-core with the LPC and is treated as two separate components. 


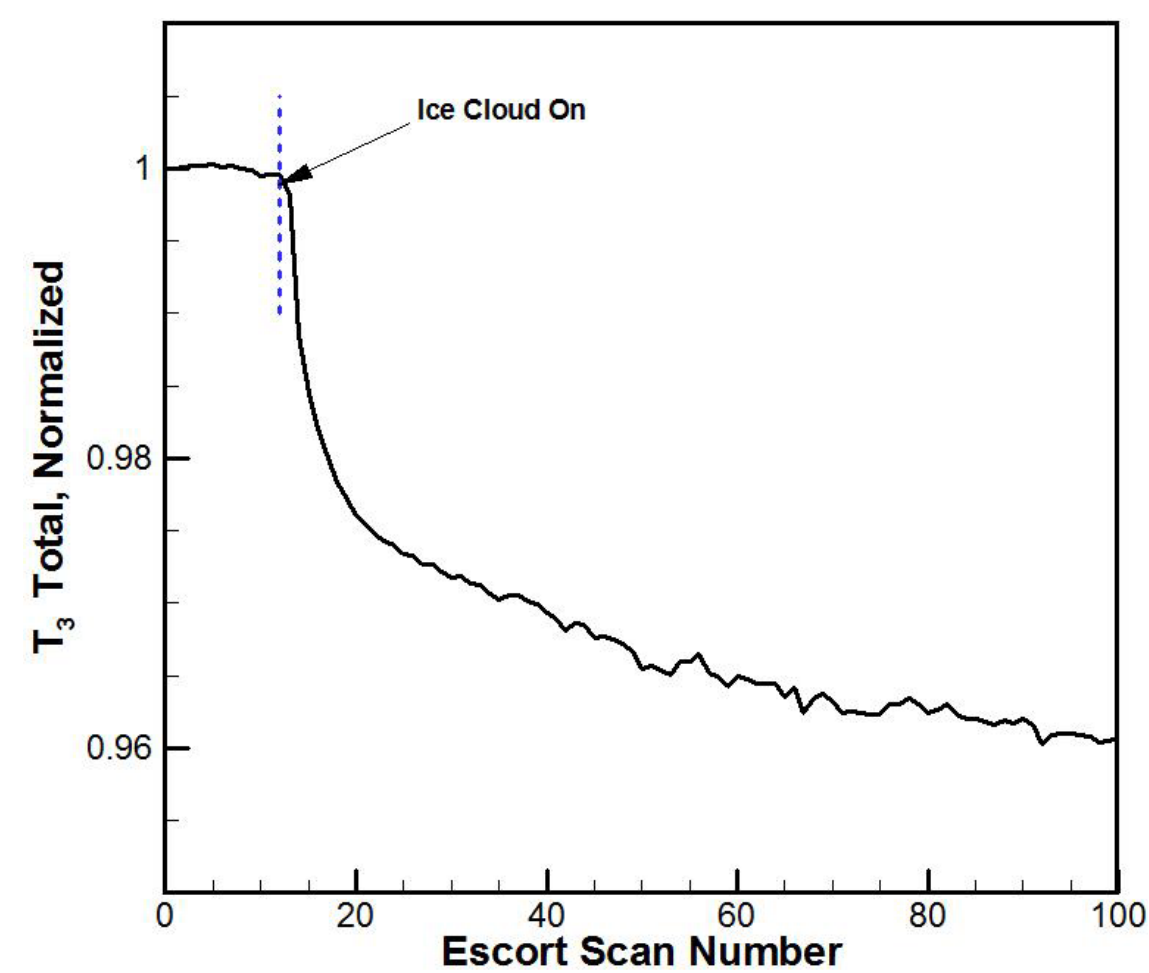

Figure 4.-The variation of measured air temperature at the high pressure compressor (HPC) exit. The air temperature decays significantly within the first few seconds after the ice cloud is initiated. It is theorized that this is due to latent heat of vaporization of the ice in the HPC.

the NPSS model in steady-state off-design mode over a series of analysis points would accurately simulate engine behavior during the roll back event through Escort scan 310. This study did not consider modeling the engine performance beyond Escort scan 310, after which the engine rolled back abruptly to even lower performance levels.

The heat transfer effects due to ingestion of the ice particles were applied in two locations in the NPSS model. The amount of thermal energy required to raise the temperature of the incoming mass of ice particles to $491.7 \mathrm{R}\left(32^{\circ} \mathrm{F}\right)$ from ambient temperature and fully melt them was determined and subtracted from the enthalpy of the air at the LPC exit (shown as Q1 at duct25 in Fig. 3); this was a relatively small adjustment of about 10 percent of the total heat loss from the air through the compression system (fancore/LPC/HPC). However the bulk (90 percent) of the thermal energy was extracted in the HPC, where it was required that the incoming mass of water particles had to be fully evaporated and raised to the HPC exit temperature. As the air flow proceeded to the high pressure compressor component, the melted ice particles continued to gain thermal energy from heating by the compressed air. Since the standard NPSS compressor component assumes an adiabatic compression process, it was decided to correct the HPC element performance using an assembly consisting of eight compressors, each representing a single stage of the HPC. Between each compressor/stage element a duct element was placed which allowed for the removal of heat from the air to simulate energy transfer from the air flow to the water particles. At the nominal design point, each HPC stage was assumed to have the same polytropic efficiency and specific work; at off-design a performance characteristic map for each stage similar to a single stage fan was used. This stage-by-stage assembly was used to provide a correction to the nominal HPC component performance, with an additional correction to the HPC required power (PWR1 in Fig. 3). This correction was used to reconcile the HPC element calculated power to the non-adiabatic compression process required power. 
The amount of enthalpy loss from the air to the particles was based on the amount of energy required to heat the water to $671.7 \mathrm{R}\left(212^{\circ} \mathrm{F}\right)$, convert it to vapor, and further raise its temperature to the HPC exit temperature (shown as Q2 at bld3 in Fig. 3). This total energy transfer was, by assumption, divided equally between each stage of the HPC. The majority of the heat transfer from the air to the water particles occurs through the HPC, which was about 90 percent of the total heat loss in the fancore/LPC/HPC. These calculations assumed that the entire mass flow rate of ice entering the core was converted to high temperature vapor, despite the obvious fact that some portion of ice was accreting within the LPC booster. As the engine conditions continued to change during the NPSS simulation of engine roll back, the amount of heat transfer was calculated based on the current amount of mass flow of air and ice particles entering the core and the temperatures throughout the compression system.

As the effects of ice accretion on the LPC stators degraded its performance through the roll back, the pressure ratio and efficiency in NPSS steadily decreased for any given flow and rotational speed. The degradation was split equally between pressure ratio and efficiency and was continued to an ultimate 96 percent degradation of both, where the LPC pressure ratio was about 1.01 with an efficiency of 3 percent. At this point the LPC was considered fully degraded; the scalars were held constant while increasing the stagnation pressure loss in the gooseneck duct and support strut following the LPC component (duct25).

Engine fuel flow was varied along a characteristic schedule of the ratio of fuel flow rate to HPC exit pressure (Wf/P3) compared to shaft speed, which the engine control system attempts to follow. The values and limits for the test engine operational schedule were not explicitly known; by evaluation of the actual PSL test data a linear function of high pressure spool rotational speed versus $\mathrm{Wf} / \mathrm{P} 3$ was found to be acceptable.

The performance of the engine during roll back was modeled with NPSS and COMDES (described in the following section) at discrete values of fan-core plus LPC degradation, with the resulting engine performance parameters plotted against the test data in Figure 5. In order to match a specific NPSS result

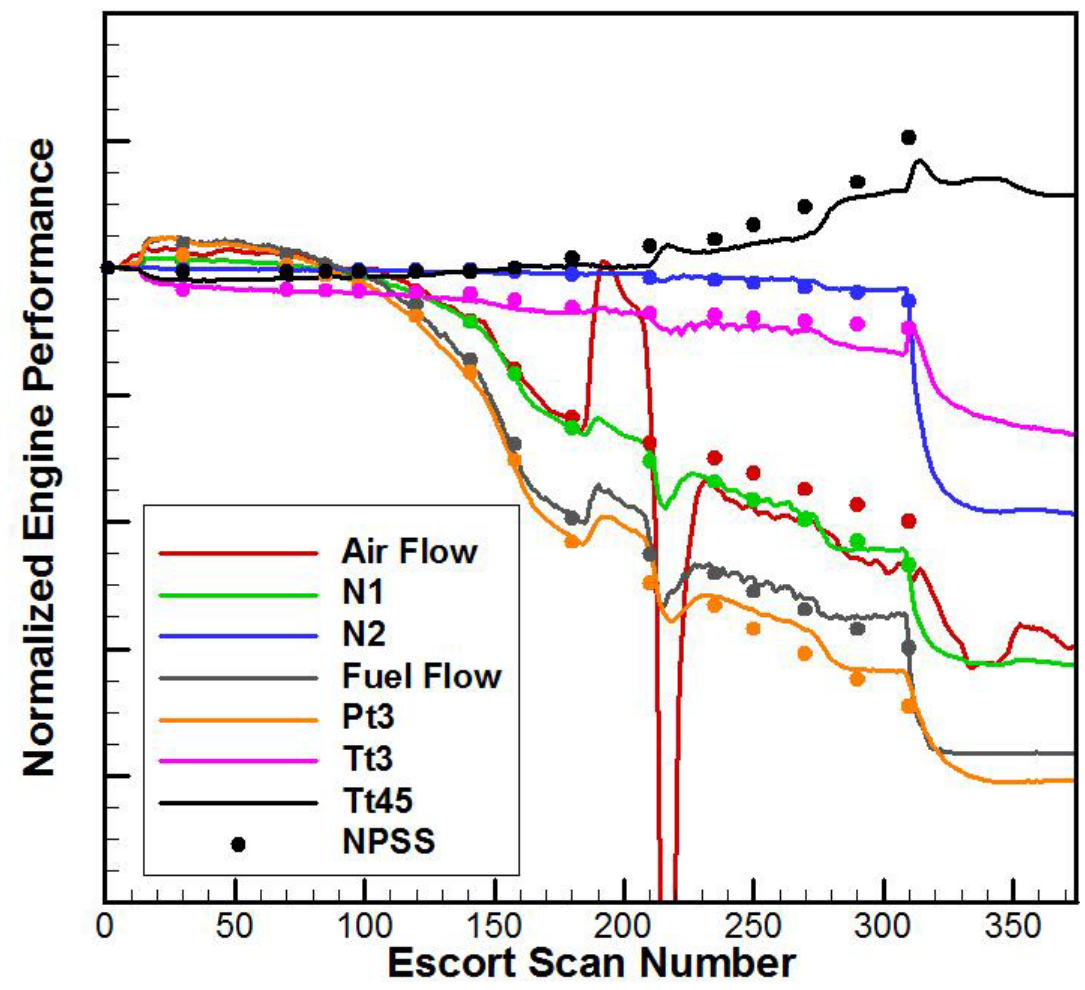

Figure 5.-The variation of measured engine parameters compared to the quasi-steady state NPSS engine system simulation through the full engine roll back event. 


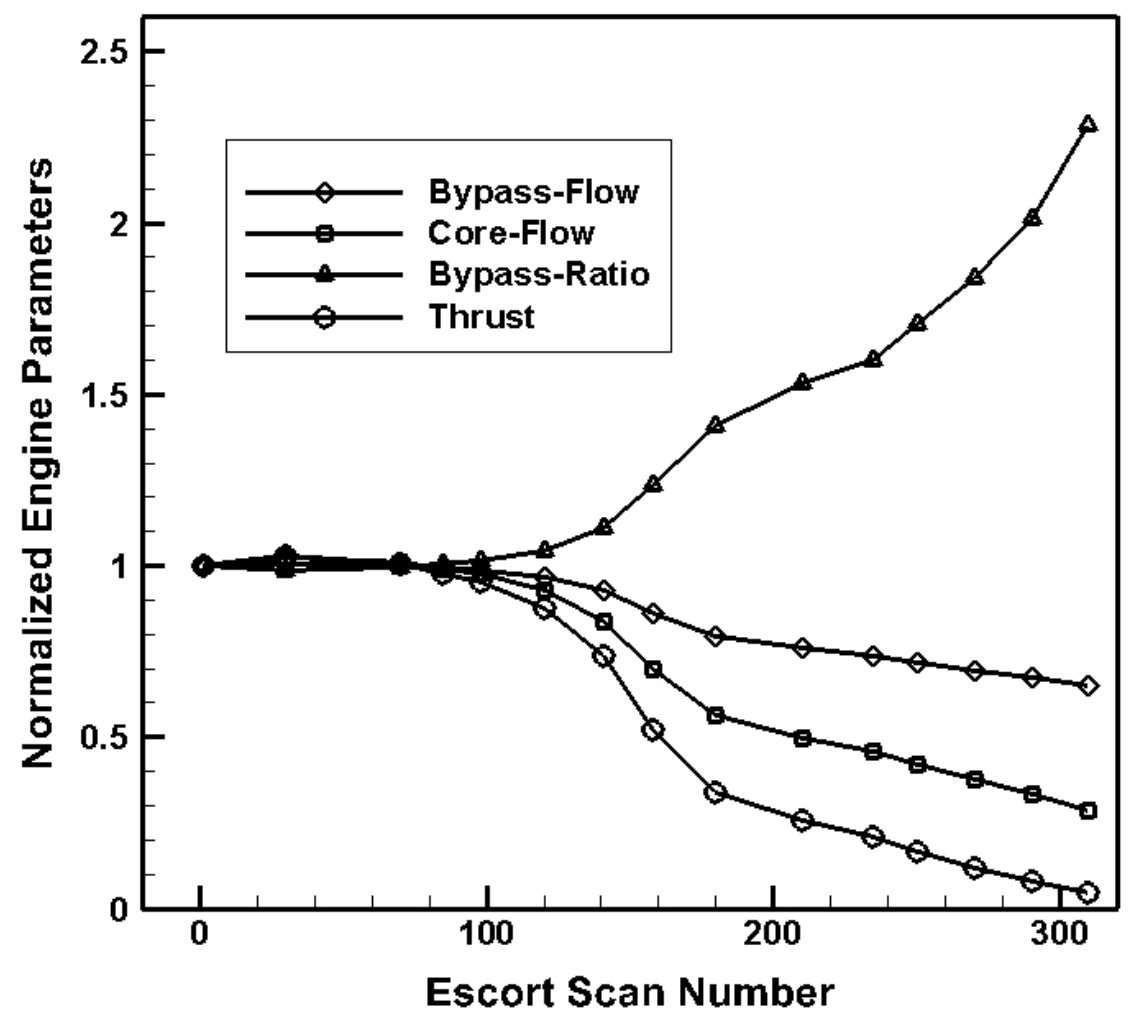

Figure 6.-Normalized engine flow rates, bypass ratio and engine thrust as estimated by the NPSS engine system model, versus Escort scan number. Here the split of flow between the bypass and the core is illustrated as the ice accretes and power is extracted in the HPC. The eventual outcome was a significant decrease in engine thrust, the condition known as engine roll back.

to a particular scan number, the NPSS data was plotted at a scan value at which the NPSS value of N1 and the test data N1 matched; these scan values were 1, 30, 70, 85, 98, 120, 141, 158, 180, 210, 235, 250, 270, 290 , and 310 . The point at which the fan-core plus LPC map scalars were fully degraded is plotted as scan 180 . The scan rate is approximately equal to one scan per second.

The NPSS simulation of the engine roll back event indicated that the engine bypass ratio increases significantly as the Escort scan number increases, as illustrated in Figure 6. Likewise, the air flow rate through the engine core decreases significantly throughout the roll back. The fan bypass flow rate decreases, even though the bypass flow ratio increases significantly, as illustrated in Figure 6 . The engine thrust reduces to 4 percent of the nominal at Escort scan 310, indicating that the thermodynamic cycle can barely be sustained. Escort data point 940 demonstrated this uncommanded loss of thrust on the PSL test stand, which is also referred to as an engine roll back event.

\section{Flow Analysis of LPC With Mean Line Compressor Model (COMDES)}

The COMDES and the NPSS codes were run independently, with the NPSS results providing the target pressure ratio and efficiency for the COMDES simulation of the fan-core and LPC. This process is illustrated in more detail in Figure 7, where the codes and their functionalities that have been utilized in this study are described in more detail. The codes are outlined with the rectangular shaped border, while the boundary condition information that is passed between the codes has borders with rounded corners. 


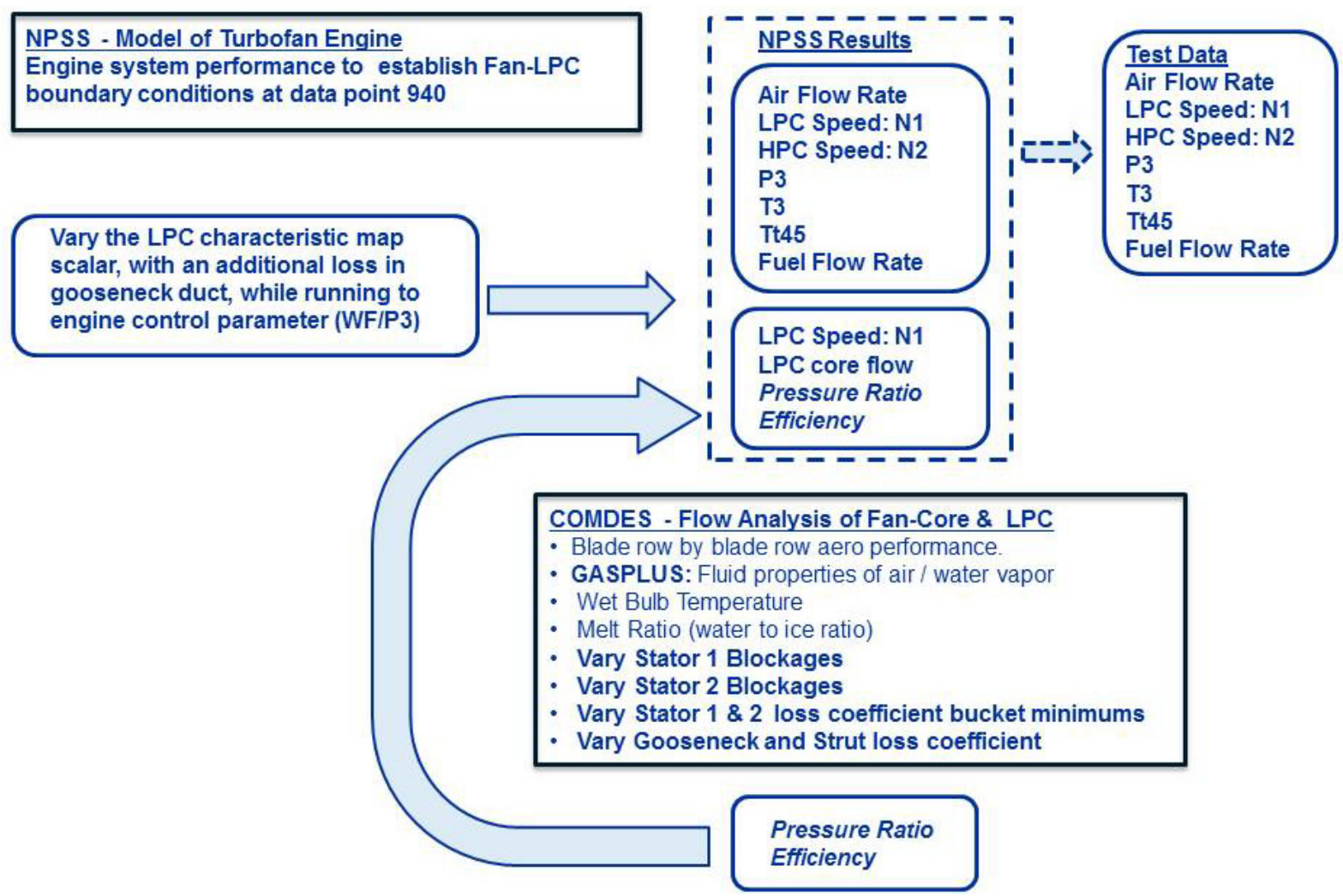

Figure 7.-The NPSS engine system model and the COMDES compressor flow model strategy for the fan-core and LPC to match test data. The NPSS model and the COMDES model are executed independently.

The next step in the modeling effort was to attempt to duplicate the NPSS model results for the degraded LPC performance, using the COMDES compressor flow analysis code. In order to perform the flow analysis it was necessary to model the detailed geometry such that the flow conditions between each blade row could be computed.

Figure 8 illustrates a representation of the fan-core and low pressure compressor cross section. Note that there is a notional streamline that is utilized in the compressor flow model that represents the cutwater between the air flow that enters the fan bypass duct, and the flow that enters the core. This streamline is utilized in the mean line model as the imaginary outer flow path of the fan-core rotor. This engine features a heated spinner and a heated fan core stator row (inlet guide vane - IGV) shown in Figure 8 that are not modeled. The tandem stators in the low pressure compressor stage (exit guide vanes - EGV) are also shown in the figure. Note that the compressor model also includes the flow analysis through the duct downstream of the EGV (sometimes referred to as a gooseneck), as well as the flow analysis through the support struts.

A compressor flow model with the COMDES code represents the fan-core and LPC in the NPSS engine system model, as was shown in Figure 3. The fan-core is followed by a single stage LPC having a tandem stator exit guide vane (EGV). The core mass flow, the fan rotational speed, the inlet pressure, inlet temperature and the degraded pressure ratio and efficiency were used as boundary conditions for the compressor flow analyses.

Figure 9 illustrates the baseline pressure ratio characteristic map of the fan-core and LPC that was generated with COMDES, without ice accretion (prior to ice cloud initiation). 


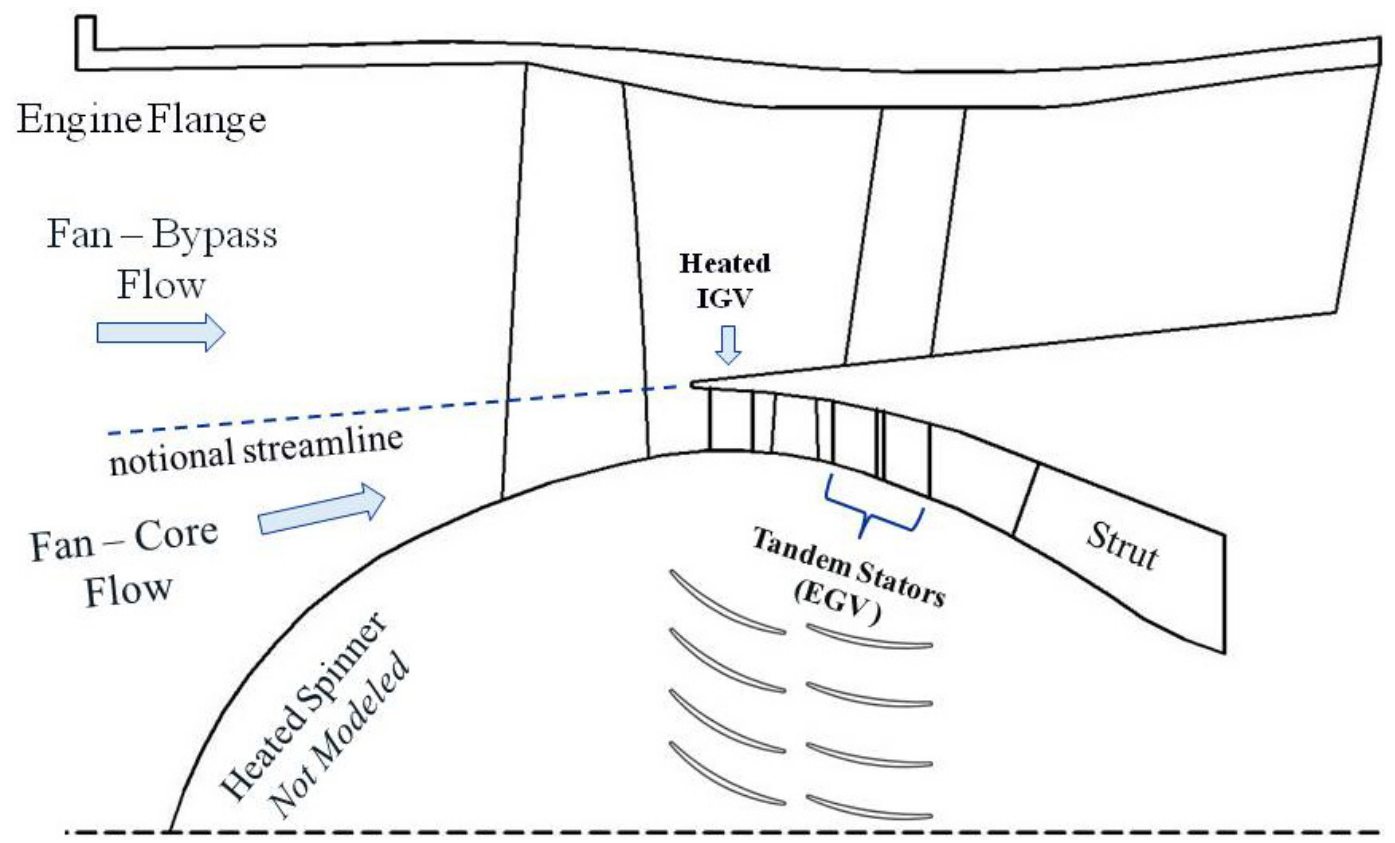

Figure 8.-Schematic of the fan and low pressure compressor portion of the engine tested in the PSL with ice crystal ingestion.

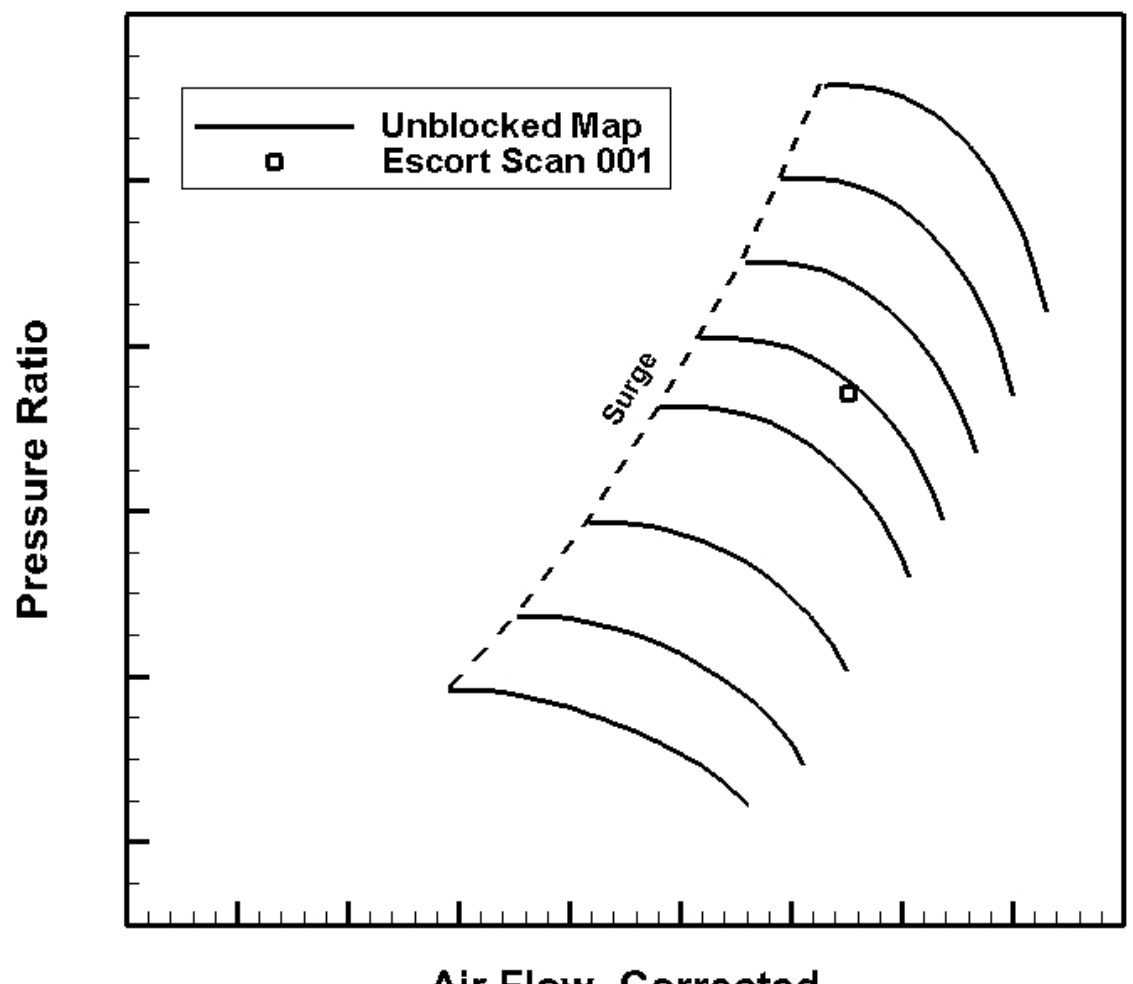

Figure 9.-Fan-core and LPC pressure ratio generated by the compressor flow analysis model, showing the baseline performance of PSL data point 940; Escort scan number 001 prior to turning on the ice cloud. 


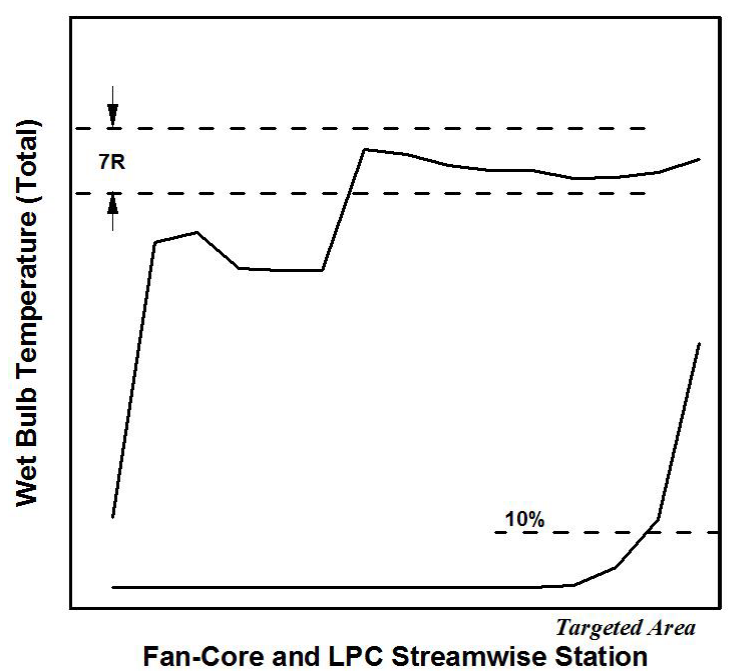

(a)

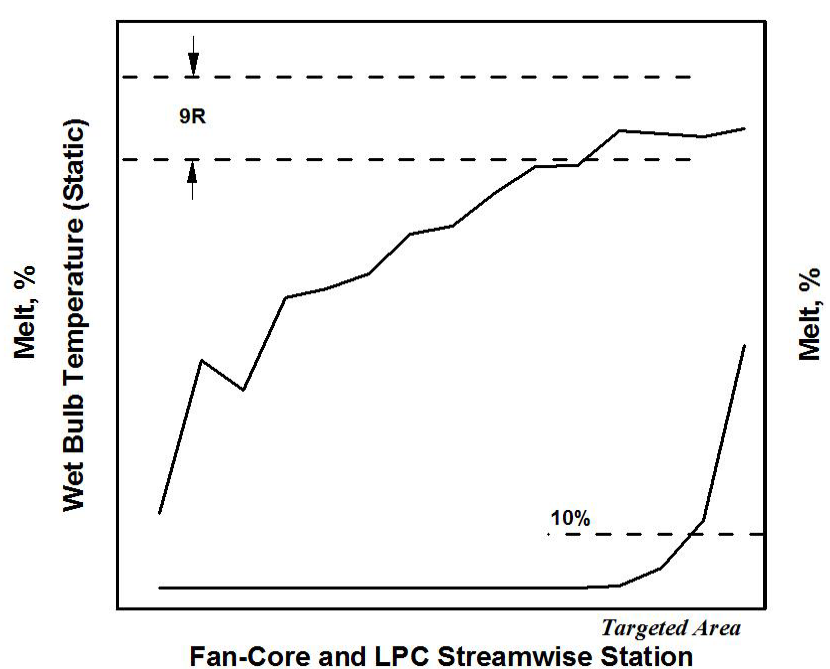

(b)

Figure 10.-Streamwise distribution of wet bulb temperature through the fan-core and LPC, gooseneck and support strut. (a) Wet bulb temperature based on total temperature, (b) wet bulb temperature based on static temperature.

\section{Icing Risk Analysis}

The conditions where there is a risk of ice accretion were determined in References 7 and 8, based on the values of wet-bulb temperature and the melt ratio, the two key parameters that together are the necessary conditions for accretion. It is recognized that other parameters such as the heat transfer rate through the blades may need to be considered as well, but are not included in these studies. The icing risk analysis of data point 940 was determined to be within the range of test data that experienced a fast rate of ice accretion, as is illustrated in Figures 10(a) and (b).

The figures above illustrate the wet bulb temperature and melt ratio for this data point prior to ice cloud initiation that satisfy the previously established icing risk criteria, as determined for this engine in References 12 and 13, since it falls within the narrow band of wet bulb temperature in the targeted area of the fan-core and LPC flow path.

\section{Compressor Analysis With Additional Blockage to Simulate the Effects of Accretion}

The results of the NPSS system model with the degraded component performances were utilized as input to the compressor flow analysis code, for more detailed analysis. Although there is no ice accretion model in the compressor flow analysis code, the effects of accretion are modeled by means of an additional blockage term to simulate the reduction in available aerodynamic area. The shape of the ice that accretes on the vanes is likewise unknown, but the effects of the accretion are applied iteratively in the code through additional loss terms, and together with the additional blockage term negatively affect the pressure ratio and efficiency. The magnitude of the blockage and the total pressure loss coefficient were increased simultaneously, until the overall pressure ratio and efficiency matched the NPSS results, as illustrated by the process diagram in Figure 7. The assumption was that matching the NPSS results will result in an accurate compressor flow model that represents the fan-core and LPC performance, since the NPSS results matched the engine test data measured in the PSL. With the above technique, the result of the compressor flow analysis matched the overall pressure ratio and efficiency results from the NPSS model with reasonable accuracy, as illustrated in Figure 11. 


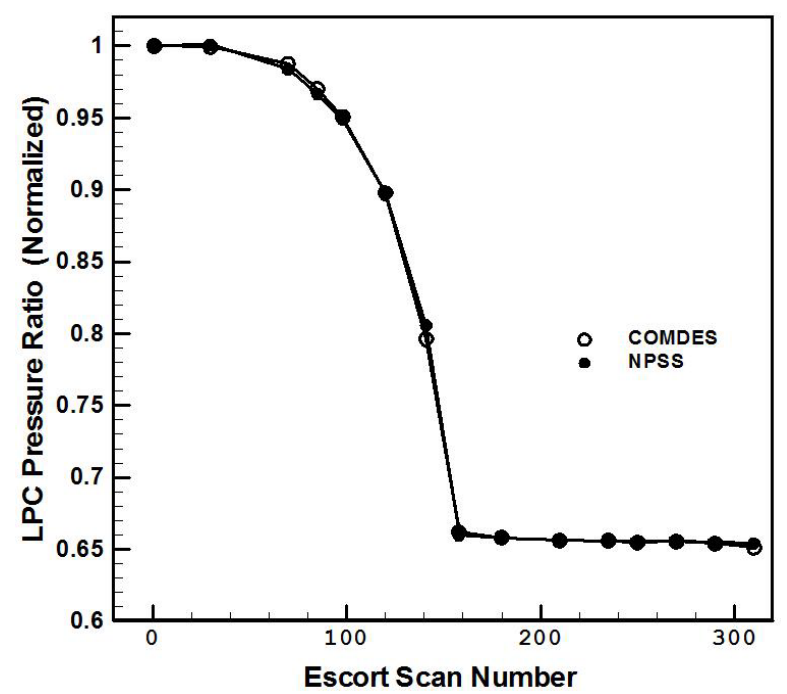

(a)

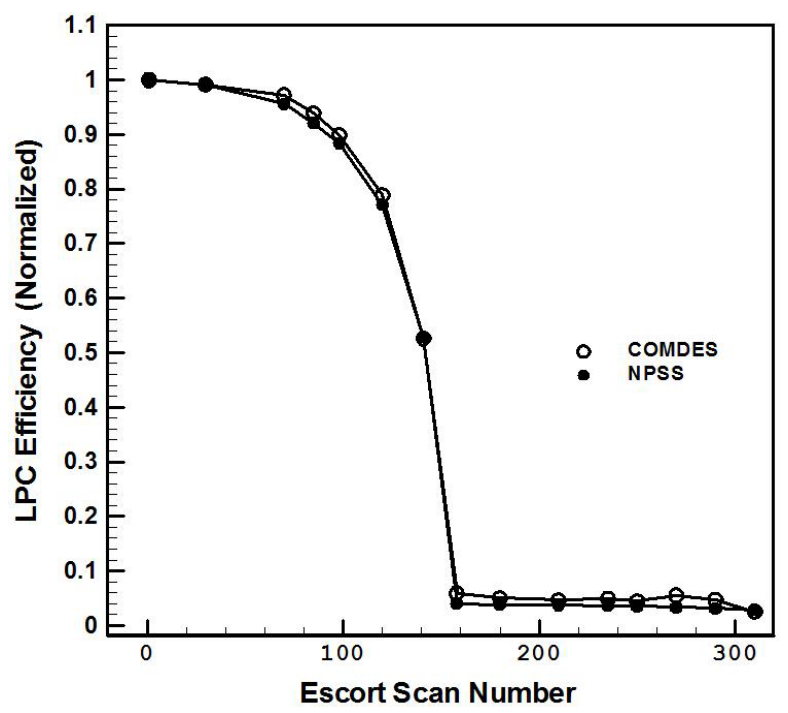

(b)

Figure 11.-The fan-core and LPC pressure ratio (a) and efficiency (b) as modeled with NPSS, compared to the compressor flow code model results, versus Escort scan number.

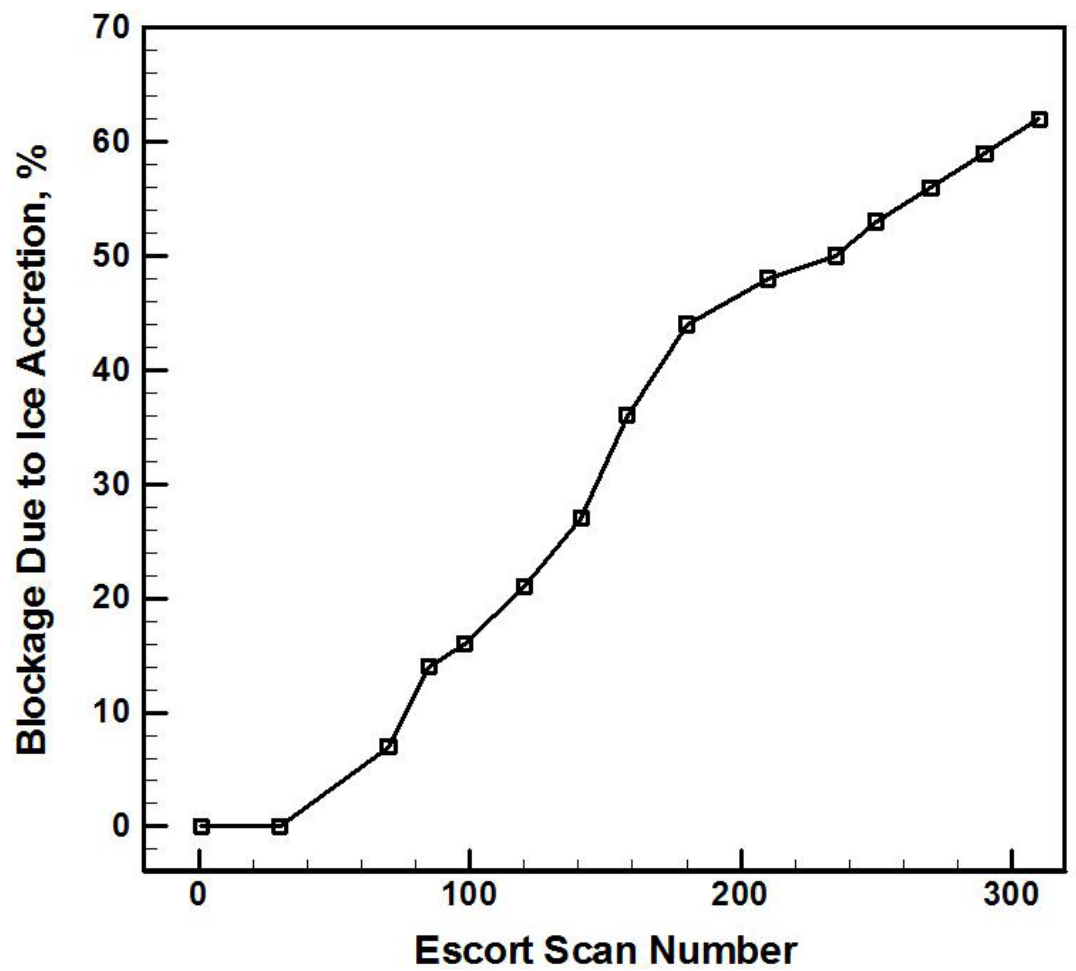

Figure 12.-The estimated blockage due to ice accretion, at the EGV stator 1 and stator 2 that was utilized in compressor flow model to match the NPSS system model pressure ratio and efficiency of the fan-core LPC.

The above procedure was applied to each Escort scan that was analyzed with the NPSS engine code through the engine roll back up to Escort scan number 310. Figure 12 illustrates the amount of additional blockage that was applied to the EGV stators and represents the reduction in available aerodynamic flow area percentage, for each Escort scan number that was analyzed in this study. Note that in order to match the pressure ratio and efficiency from the NPSS simulations at each Escort scan number, the amount of required blockage increased in a near linear rate. 
The value of blockage in the EGV starts to increase at scan number 60, which is approximately 50 sec after the ice cloud is initiated. By Escort scan number 180, the available aerodynamic area is reduced to 45 percent, and rises to above 60 percent by scan number 310 . As the ice accretes on the EGV stator vanes, the available aerodynamic area decreases due to additional blockage caused by the buildup of ice, as illustrated in Figures 12, resulting in increased level of incidence on both stators 1 and 2 as illustrated in Figure 13.

The increased incidences at the rotor and stator leading edges result in increased levels of losses. In addition to the standard losses caused by increased levels of incidence, there is also an additional increase in losses resulting from the increased surface roughness caused by a coating of ice. The additional losses that were utilized in the compressor flow model were determined iteratively, simultaneously with the level of blockage, in order to match the overall pressure ratio and efficiency computed by the NPSS system model. Figure 14 illustrates the additional pressure losses that were utilized in the compressor flow model, as a function of Escort scan number. Note that the losses represent the loss bucket minimum points in the incidence versus loss model within the code. The resulting overall loss coefficient through the component is the combination of incidence losses as well as the applied additional losses shown in Figure 14.

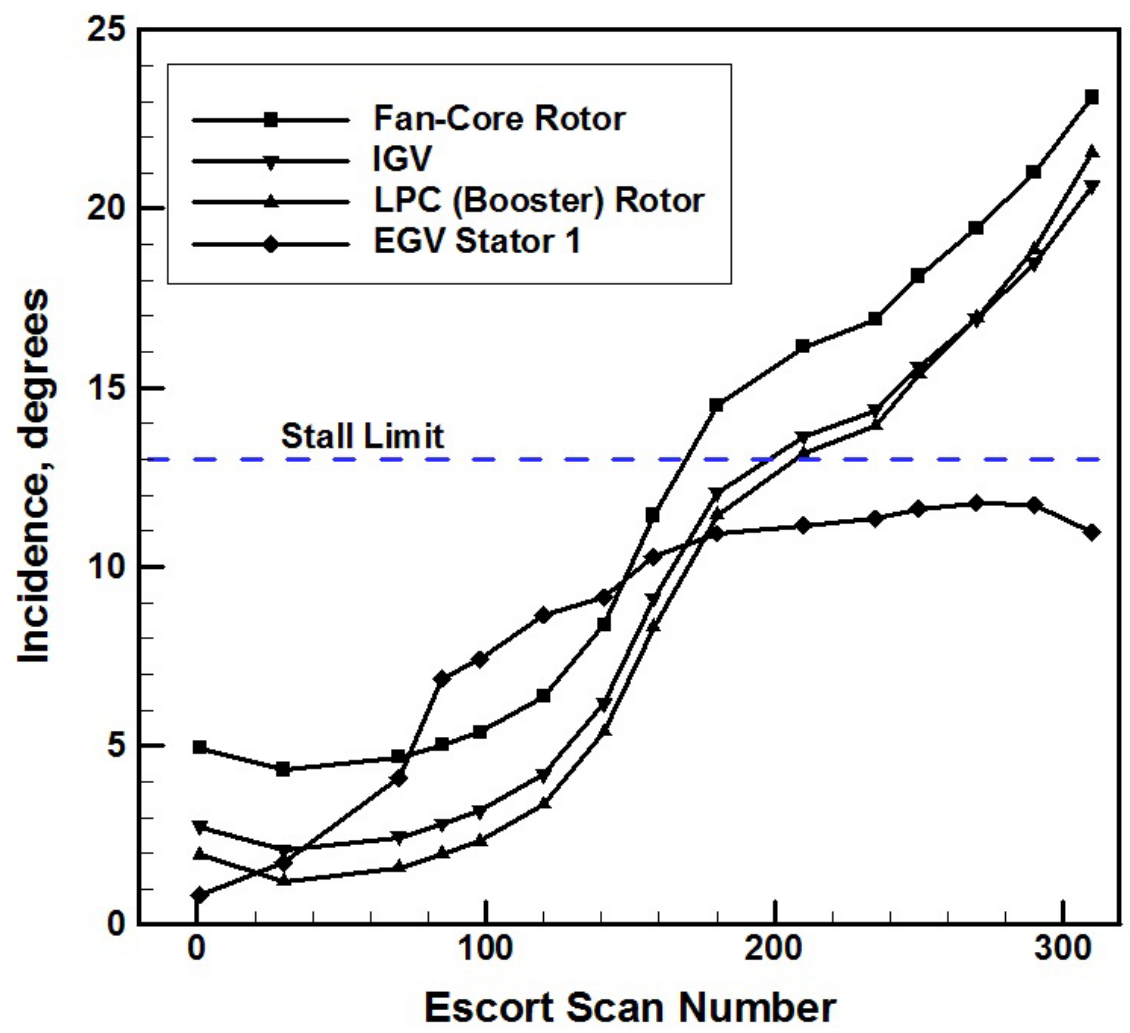

Figure 13.--Incidence angle of fan-core rotor, LPC rotor, IGV, and EGV stator 1, versus Escort scan number. Note, incidences above $13^{\circ}$ may indicate stall, or separated flow, resulting in flow reversals. 


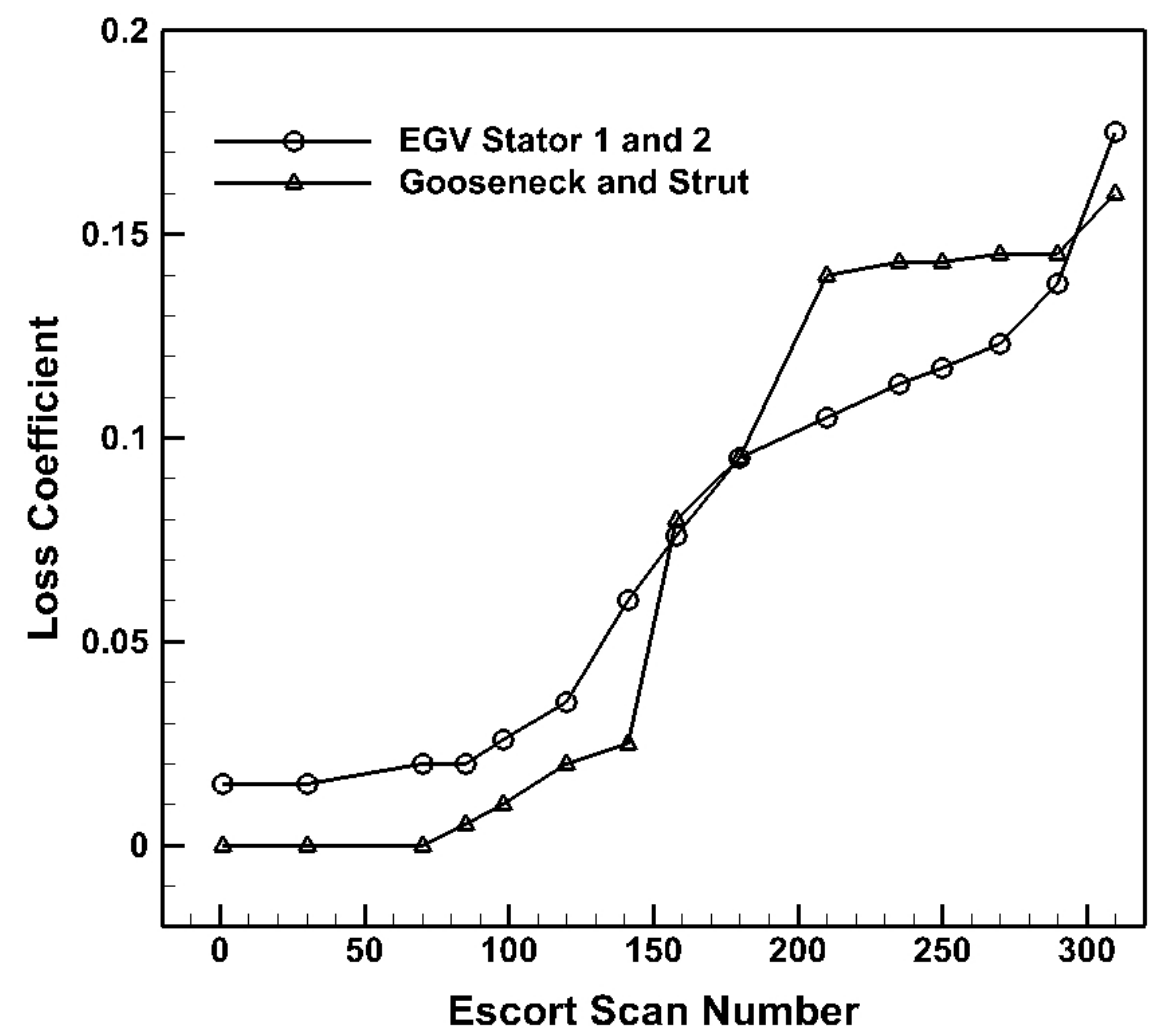

Figure 14.- - he loss bucket minimum points of the total pressure loss coefficient of the EGV tandem stators 1 and 2, and the gooseneck and support strut. The increased loss is attributed to increase in ice accretion.

The pressure loss coefficients for each component rise rapidly with Escort scan number. The losses in Figure 14 are applied to the EGV stators 1 and 2, as well as the gooseneck and support strut. The stators 1 and 2 have the same loss coefficients; likewise the gooseneck and strut also have the same loss coefficients. The pressure loss coefficient $(\omega)$ is defined by the following equation, where $P_{\text {Tin }}$ and $P_{\operatorname{Sin}}$ are the total and static pressures at the component inlet, while the $P_{\text {Tout }}$ is the total pressure at the exit of the component.

$$
\omega=\frac{\left(P_{\text {Tin }}-P_{\text {Tout }}\right)}{\left(P_{\text {Tin }}-P_{\text {Sin }}\right)}
$$

The compressor flow analysis results indicate that the rotor and stator incidences rise above $13^{\circ}$ by Escort scan number 180, and indicate there may be a stall, or separated flow with flow reversals in the rotors and IGV.

The flow analysis also indicates that the relative velocity ratio through the fan-core rotor reach the surge limit at Escort scan number 180 (Fig. 15), which corroborates the stall indicator based on the $13^{\circ}$ incidence criteria.

Confirmation of compressor stall in the region of Escort scan 180 and beyond was verified by a video recording taken during the PSL engine icing test, where it was noted that there was evidence of flow reversals, e.g., water flowing upstream on the surface of the IGV vane, as shown in Figure 16. 


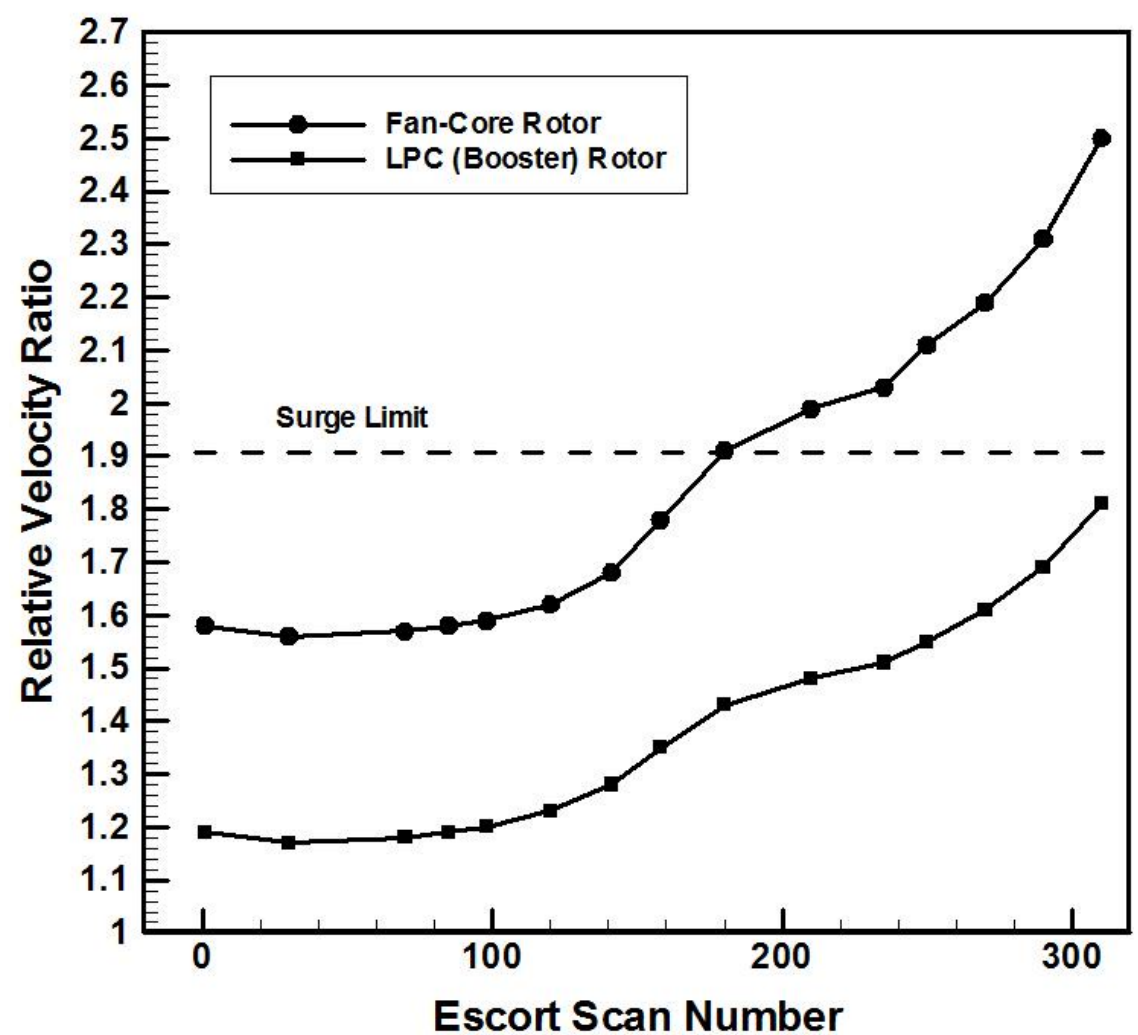

Figure 15.--Relative velocity ratio through the fan-core rotor and the LPC (booster) rotor. The surge limit is reached in the fan-core region, beyond Escort scan number 180.

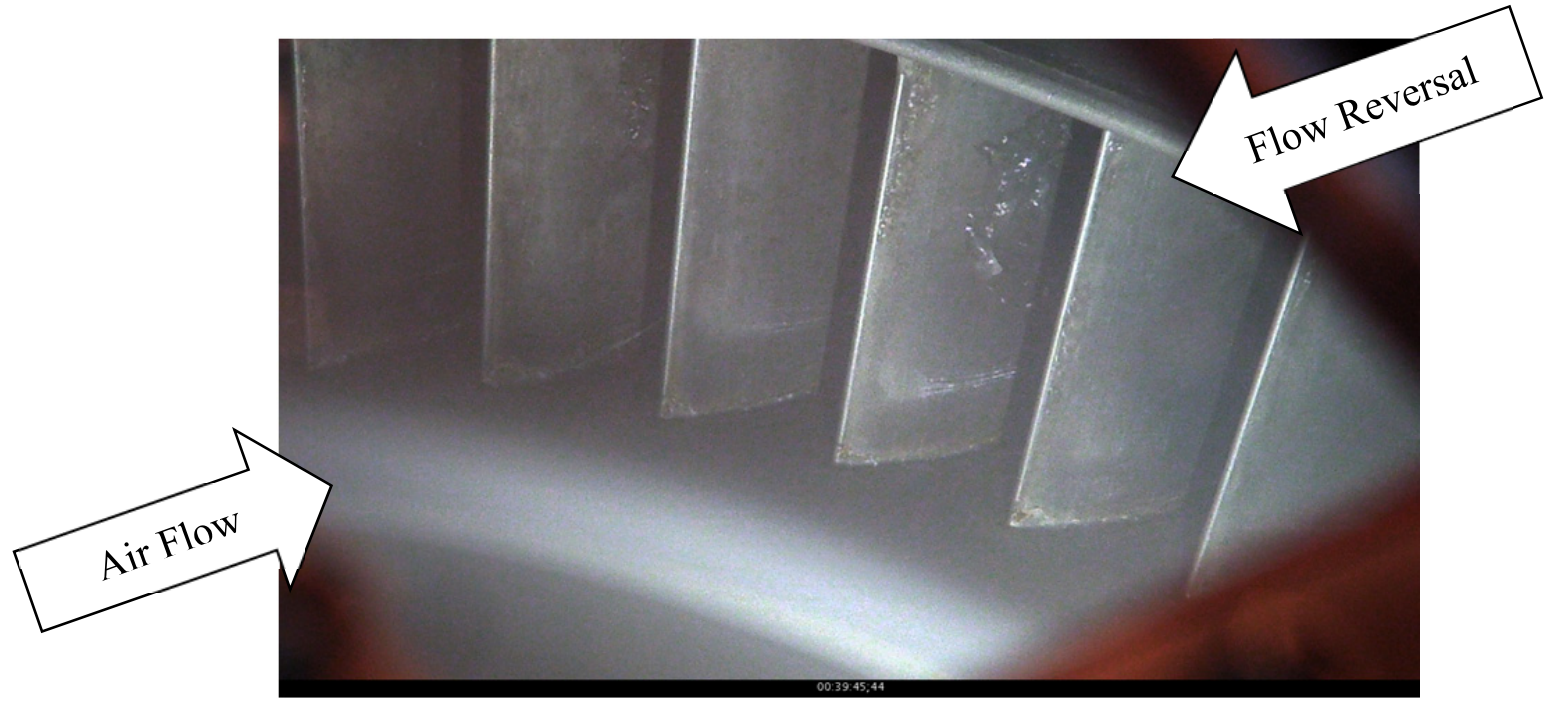

Figure 16.-Image capture from video taken during the PSL engine testing of the IGV showing water flowing upstream on the IGV surface beyond Escort scan 180. This is evidence of air flow reversal and corroborates the results of the computational flow analysis, indicating a stalled LPC. 
The video of the IGV during the PSL engine test showed the water on the IGV actually flowed upstream out of the engine, indicating that the fan-core rotor is in stall, which is characterized by flow reversal. The blockage caused by ice accretion in the EGV stators is reducing the available flow area, thereby reducing the core flow to a mere fraction of the nominal core flow without ice blockage, while the EGV is nearly choked due to the reduced flow area. The low air flow into the core is the reason the fancore rotor and stators are in stall, while the EGV is nearly choked even though the core flow rate is severely reduced.

Based on the compressor flow model, an estimate was made of the overall pressure loss coefficient through the EGV tandem stators, gooseneck and support strut, as a function of Escort scan number, as illustrated in Figure 17. It is apparent that the losses are increased drastically, and reflect the loss of overall pressure ratio and efficiency, as was illustrated in Figure 11.

The operating line of the fan-core and LPC during the engine roll back event is superimposed on its baseline characteristic performance map in Figure 18(a), as a function of Escort scan number. Note that the actual instantaneous characteristic performance map changes throughout the engine roll back event, at each Escort scan number. To illustrate the instantaneous change in the compressor characteristic maps, several maps were generated at various Escort scan numbers with the flow code, and are shown in Figure 18(b).

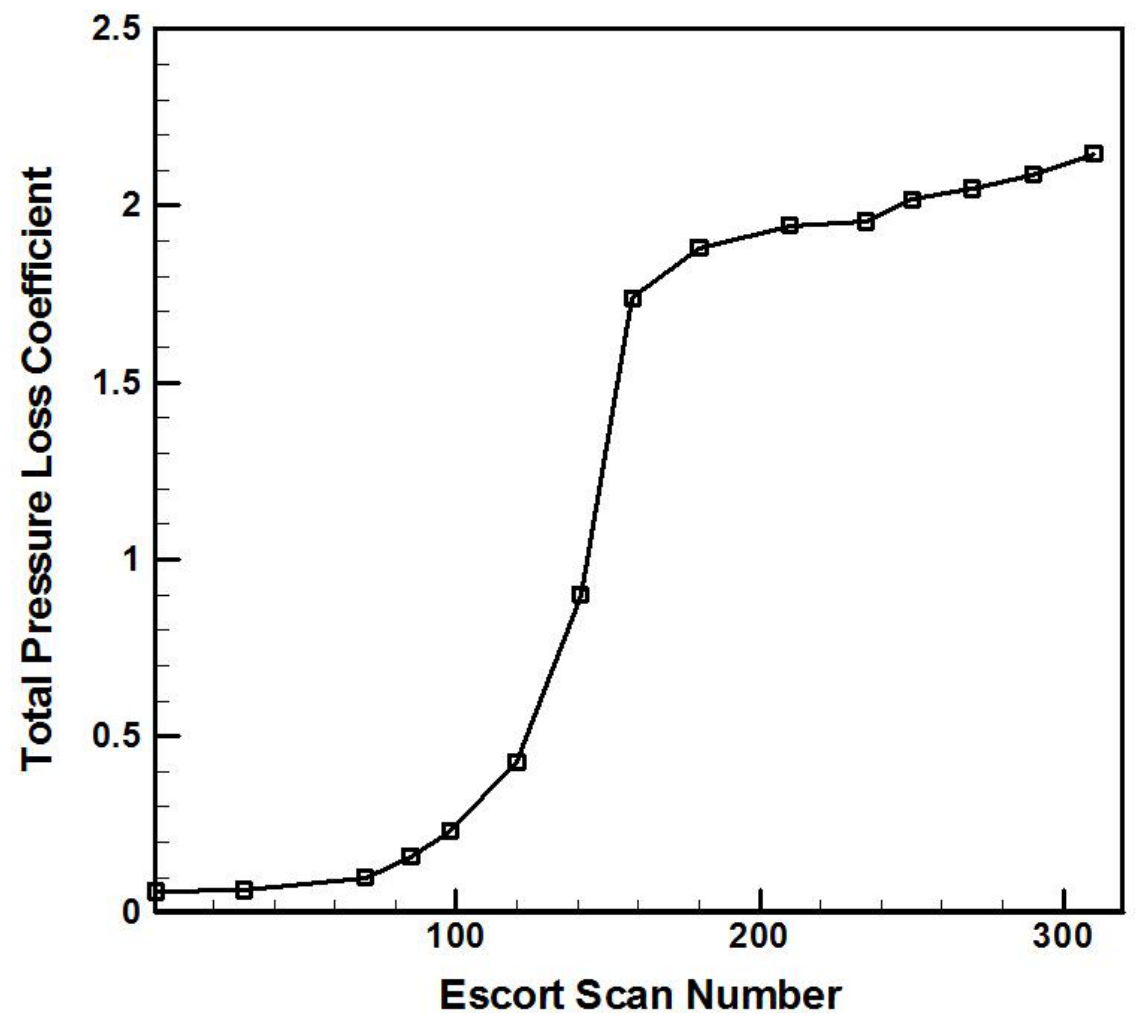

Figure 17.-The overall total pressure loss coefficient through the EGV, gooseneck and support strut. The losses are due to incidence (from Fig. 13) and the additional corrections from Figure 14 showing the reduced pressure recovery caused by the ice buildup on the vane surfaces. 


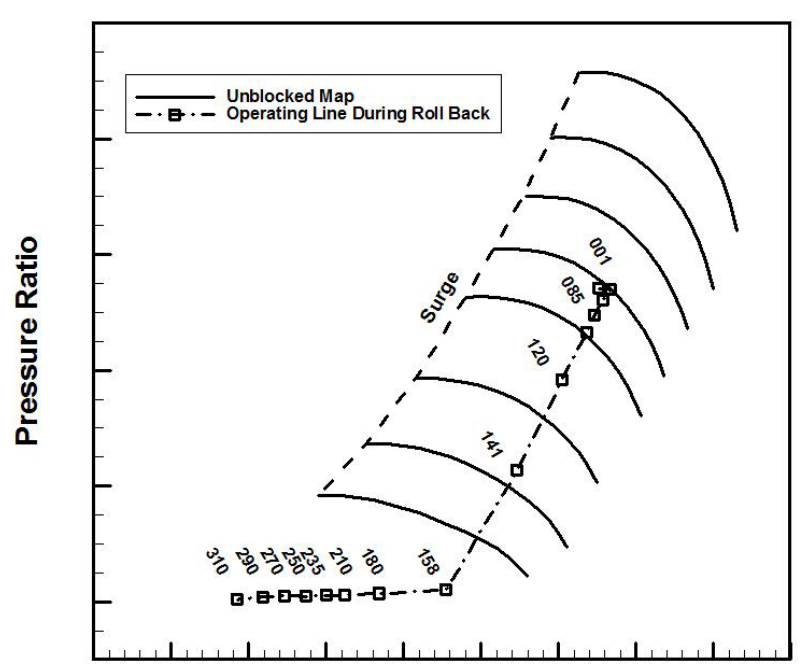

Air Flow, Corrected

(a)

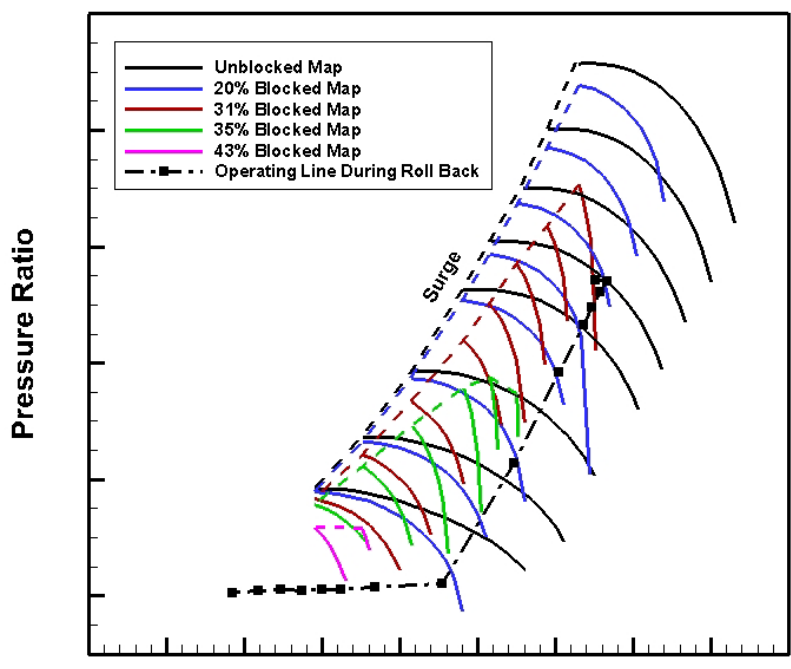

Air Flow, Corrected

(b)

Figure 18.-(a) The calculated fan-core LPC operating line through the engine roll back event of Escort data point 940, superimposed on the nominal performance characteristic map. (b) The calculated instantaneous maps for select values of blockage are illustrated.

These maps are time-dependent and represent the varying degree of blockage due to ice accretion in the EGV stators, as well as additional losses, as described above. The values for each map shown in Figure 18(b) are as follows: scan 001 (0\% blockage), scan 120 (20\% blockage), scan 150 (31\% blockage), scan 160 (35\% blockage), scan 180 (43\% blockage). Additional maps were also generated to reflect blockages up to 62 percent through scan 310 .

\section{Estimating the Rate of Ice Growth}

The blockage illustrated in Figure 12 represents the bulk effect of ice growth, as well as other effects that result in reduced available aerodynamic area, such as boundary layer thickness, increased surface roughness, and surface irregularities due to accreted ice. It is beyond the scope of this study to quantify each of these effects, therefore the combined effect of these phenomena will be referred to as the "rate of ice growth." In this study the ice growth is assumed to start at the outer wall and grow radially inward. The rate of ice growth was estimated from the EGV geometric annular area and the boundary of the ice is represented by the dashed line in Figure 19(a) utilizing the calculated values of blockage shown in Figure 12.

Figure 19(b) also shows how the ice might accrete on the stators, and is for illustration purposes only. Note that the ice accretion was not measured in this engine test and the accretion is likely not uniformly distributed on the outer wall or the stator vanes. The actual ice accretion shape might be a combination of the two illustrations 19(a) and (b), and will require further analysis with a higher fidelity ice accretion code capable of simulating viscous effects and thin airfoils with complex accreted ice shapes.

The instantaneous rate of ice growth in the EGV versus Escort scan number was obtained from the calculated values of blockage, and is illustrated in Figure 20.

The estimate of the instantaneous rate of ice growth varied between 0.001 and 0.008 in. per Escort scan number (approximately equal to inches per second), with an overall rate of ice growth on the order of 0.003 in. per second averaged over 310 Escort scans, or approximately $5 \mathrm{~min}$. This calculated rate of ice growth is in general agreement with values that were measured in laboratory experiments on an isolated airfoil as noted in Figures 14 and 15 in Reference 14. Although there is a dependence of ice growth rate on the ice-water content of the air, the results of this study are in agreement with the magnitude of ice crystal growth observed in that reference. 


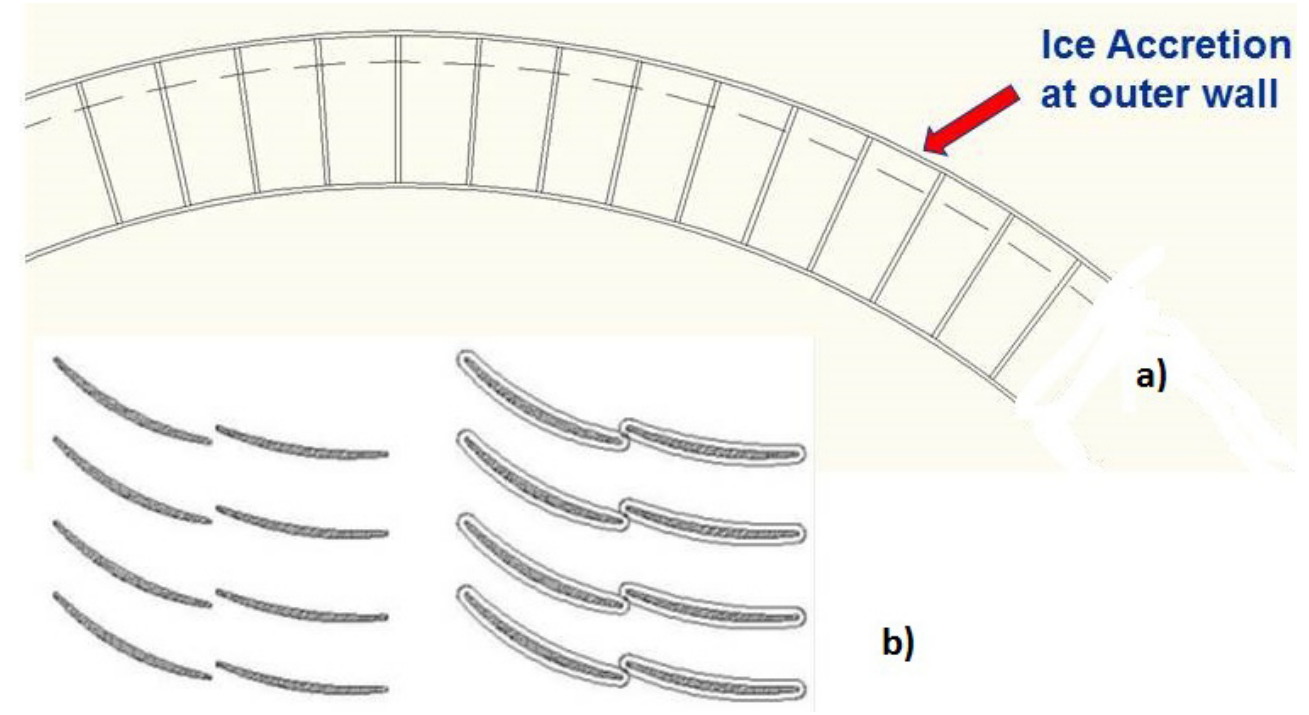

Figure 19.-(a) The area reduction due to blockage assumed that ice accretes on the outer wall in the EGV region. (b) Ice accretion shown between the EGV tandem stator blade rows is for illustration purposes only, as there is no test data to confirm how ice accreted on the EGV stator vanes.

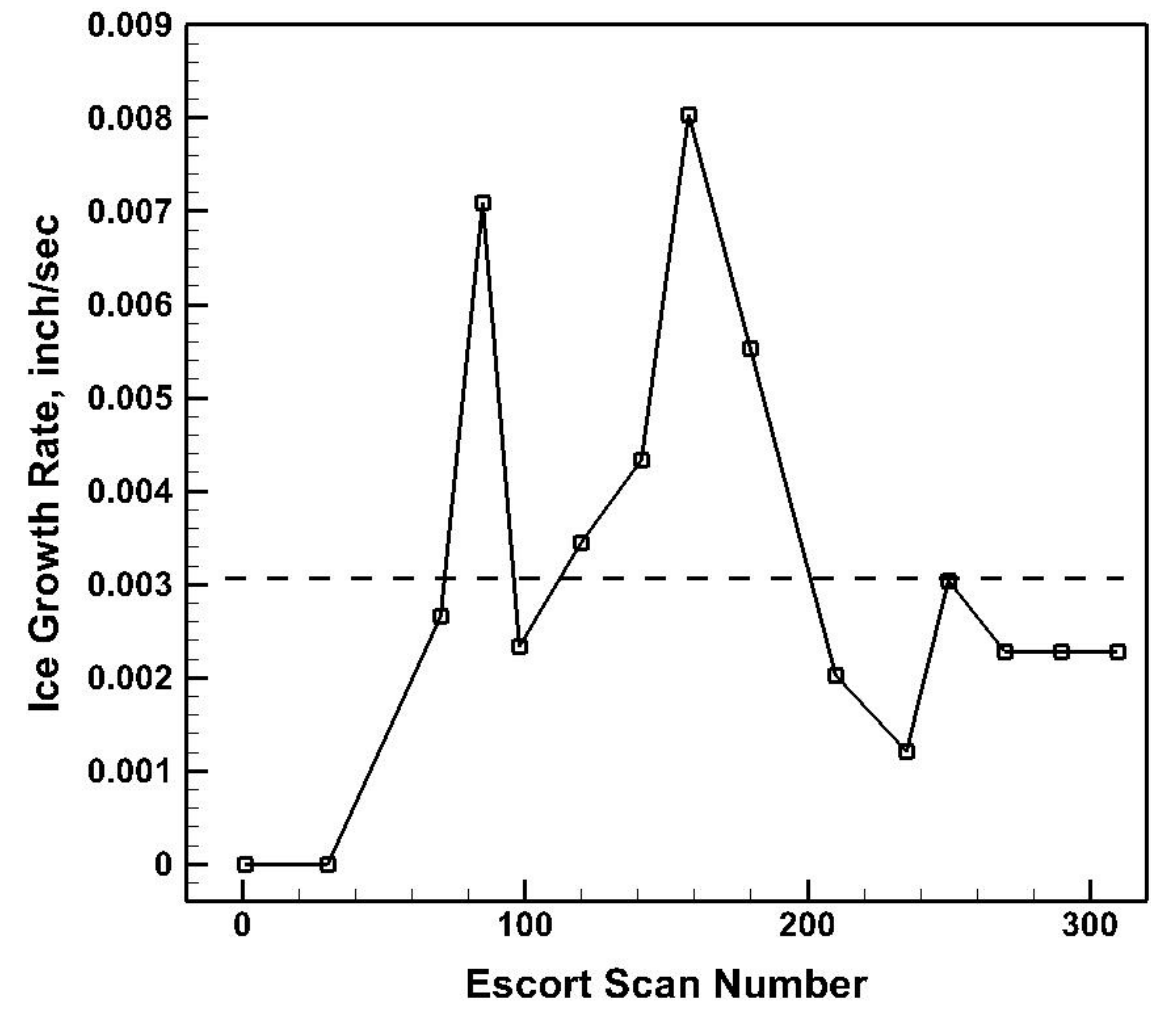

Figure 20.-The instantaneous rate of ice growth in the EGV stators due to accretion, versus Escort scan number. 


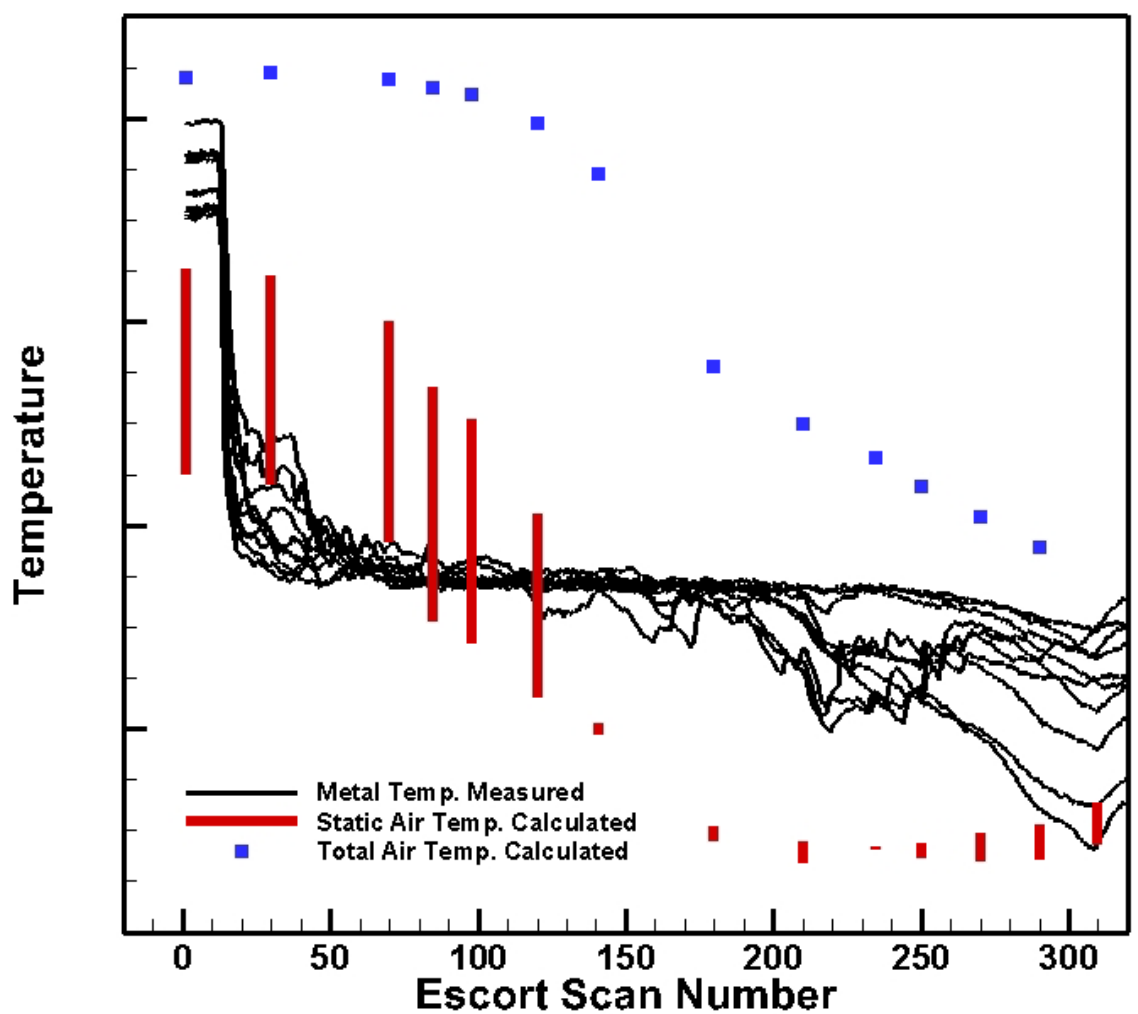

Figure 21.-Metal temperatures measured in the EGV and outer wall in the gooseneck duct. The calculated air temperatures (total and static) are also shown. The metal temperatures drop to near freezing approximately $70 \mathrm{sec}$ after the ice cloud was initiated, even more rapidly than the calculated air static temperature.

\section{Comparison of EGV Metal Temperatures to the Calculated Air Temperatures}

Figure 21 shows the measured metal surface temperatures of the EGV tandem stators and the downstream duct outer wall. The figure also shows the air total temperatures and the range of air static temperatures as calculated by the compressor flow model.

The bottom of the static temperature bar represents the air static temperature near the leading edge of the first EGV tandem stator, while the top of the bar represents the static temperature of the air at the trailing edge of the second EGV tandem stator. Prior to ice cloud initiation (Escort scan 12) the calculated total air temperatures are above the measured metal temperatures, as well as throughout the entire engine roll back event. In addition, the EGV stator metal temperature measurements before Escort scan 12 shows that the stator metal temperature values are between the total and static temperatures of the air, as expected. This is in stark contrast to the stator metal temperatures after the ice cloud is turned on, where for the first 80 Escort scans, the stator metal temperatures drop rapidly to near $492 \mathrm{R}$ (freezing), which is below the air static temperature. It is theorized that this rapid metal temperature reduction might be caused by the cooling effect of the partially melted (mixed-phase) ice particles and water droplets contacting the stator surfaces thus cooling them through conduction and evaporation. However, beyond Escort scan 120, the air static temperature decreases to well below the sub-freezing metal temperatures. 


\section{Discussion and Future Research}

Since this engine test had limited instrumentation, the NPSS system model and the low fidelity compressor flow model were used to estimate the pressures and temperatures and other flow parameters in the targeted region of the EGV where there were no instrumentation. The approach to model the flow with low fidelity codes was selected for this study primarily to provide a fast capability to determine the global effects of blockage due to ice accretion on the performance degradation of the fan-core and LPC, during the engine roll back event. Future work will involve testing this engine with significantly more instrumentation within the region of the IGV, in order to validate the calculations made in this study with the low fidelity engine icing modeling tools. The instrumentation shall include videos within the LPC flow path and provide qualitative and quantitative measurements of ice accretion location and ice growth rate. In addition, higher fidelity flow simulation tools and ice accretion prediction tools can be applied to increase understanding of the aero-thermal flow conditions throughout this engine roll back event. Further research is planned to model the effects of ice shape and the resulting roughness of the accreted ice on the surfaces of the flow path walls and stator vanes. Ice shapes that accrete on the compressor stators and walls will most likely have unusual shapes. The resulting ice shapes may likely be influenced by the unsteady air flow fluctuations between the rotors and stators. This will likely have a detrimental effect on the pressure recovery and losses, and will affect the aerodynamic matching of the downstream compressor stages, as well as the overall power balance of the engine system. These results from the heavily instrumented engine test and the high fidelity simulation can also be incorporated in the low fidelity engine icing modeling tools to improve its current capabilities. Further research is needed in the area of ice shedding to study its effect on the compressor and engine system performance.

\section{Conclusion}

A two spool turbofan engine was tested with ice crystal ingestion in the Propulsion Systems Laboratory (PSL) altitude test facility of NASA Glenn Research Center. An engine roll back event, which was experienced during flight, was successfully duplicated in the PSL test facility at simulated altitude operating conditions. During the roll back the engine experienced uncommanded loss of thrust due to ice accretion. The Escort data point number 940 engine roll back event was selected for analysis. An NPSS engine system model of the two spool turbofan engine was created to simulate the performance of the engine during the ice ingestion which resulted in the engine roll back event. The NPSS engine system model accurately simulated the engine performance deterioration during the engine roll back. It was found that the deterioration of the LPC performance and the enthalpy loss in the HPC due to the change of state of the particles accounted for the loss of engine performance. The compressor flow analysis of the LPC with additional blockage and pressure losses resulted in reasonably good agreement with the engine system model. The high values of incidence and relative velocity ratio of the fan-core rotor and LPC indicate flow separation after scan number 180. This was corroborated with a video that showed flow reversals as evidenced by water droplets moving upstream on the inlet guide vane surface. The calculated degree of additional blockage in the EGV stators due to accretion was found to be on the order of 43 percent by the time of Escort scan number 180, and 62 percent by Escort scan number 310 . The average rate of ice growth on the EGV stators calculated from the simulated values of additional blockage was on the order of 0.003 in. per second, which is in general agreement with the growth rates measured in laboratory tests, as has been reported. 


\section{References}

1. Mason, J.G., Strapp, J.W., Chow, P., "The Ice Particle Threat to Engines in Flight," AIAA-2006-206-739.

2. Mason, J.G., Chow, P., Fuleki, D.M., "Understanding Ice Crystal Accretion and Shedding Phenomenon in Jet Engines Using a Rig Test," GT2010-22550.

3. Mason, J.G., Grzych, M., "The Challenges Identifying Weather Associated With Jet Engine Ice Crystal Icing," SAE 2011-38-0094.

4. Jones, S.M., "An Introduction to Thermodynamic Performance Analysis of Aircraft Gas Turbine Engine Cycles Using the Numerical Propulsion System Simulation Code," NASA/TM-2007214690.

5. Veres, J.P., "Axial and Centrifugal Compressor Mean Line Flow Analysis Method," AIAA-2009-1641, NASA/TM-2009-215585.

6. Jorgenson, P.C.E., Veres, J.P., Wright, W.B., May, R.D., "Engine Icing Modeling and Simulation (Part I): Ice Crystal Accretion on Compression System Components and Modeling its Effects on Engine Performance," SAE Int'1., 2011-38-0025.

7. Veres, J.P., Jorgenson, P.C.E., Wright, W.B., Struk, P., “A Model to Assess the Risk of Ice Accretion due to Ice Crystal Ingestion in a Turbofan Engine and its Effects on Performance," AIAA-2012-3038.

8. Veres, J.P., Jorgenson, P.C.E., Wright, W.B., "Modeling the Effects of Ice Accretion on the Low Pressure Compressor and the Overall Turbofan Engine System Performance," NASA/TM-2013217034.

9. Jorgenson, P.C.E., Veres, J.P., Wright, W.B., Struk, P., “A Model to Assess the Risk of Ice Accretion due to Ice Crystal Ingestion in a Turbofan Engine and its Effects on Performance," NASA/TM-2013-218094.

10. Oliver, M.J., "Validation Ice Crystal Icing Engine Test in the Propulsion Systems Laboratory at NASA Glenn Research Center," AIAA-2014-2898.

11. Goodwin, R.V., Dischinger, D.G., "Turbofan Ice Crystal Rollback Investigation and Preparations Leading to Inaugural Ice Crystal Engine Test at NASA PSL-3 Test Facility," AIAA-2014-2895.

12. Veres, J.P., Jorgenson, P.C.E., "Modeling Commercial Turbofan Engine Icing Risk with Ice Crystal Ingestion," AIAA-2013-2679.

13. Veres, J.P., Jorgenson, P.C.E., Coennen, R., "Modeling of Commercial Turbofan Engine with Ice Crystal Ingestion; Follow-On," AIAA-2014-2899.

14. Struk, P., Lynch, C.J., "Ice Growth Measurements from Image Data to Support Ice-Crystal and Mixed-Phase Accretion Testing," AIAA-2012-3036. 



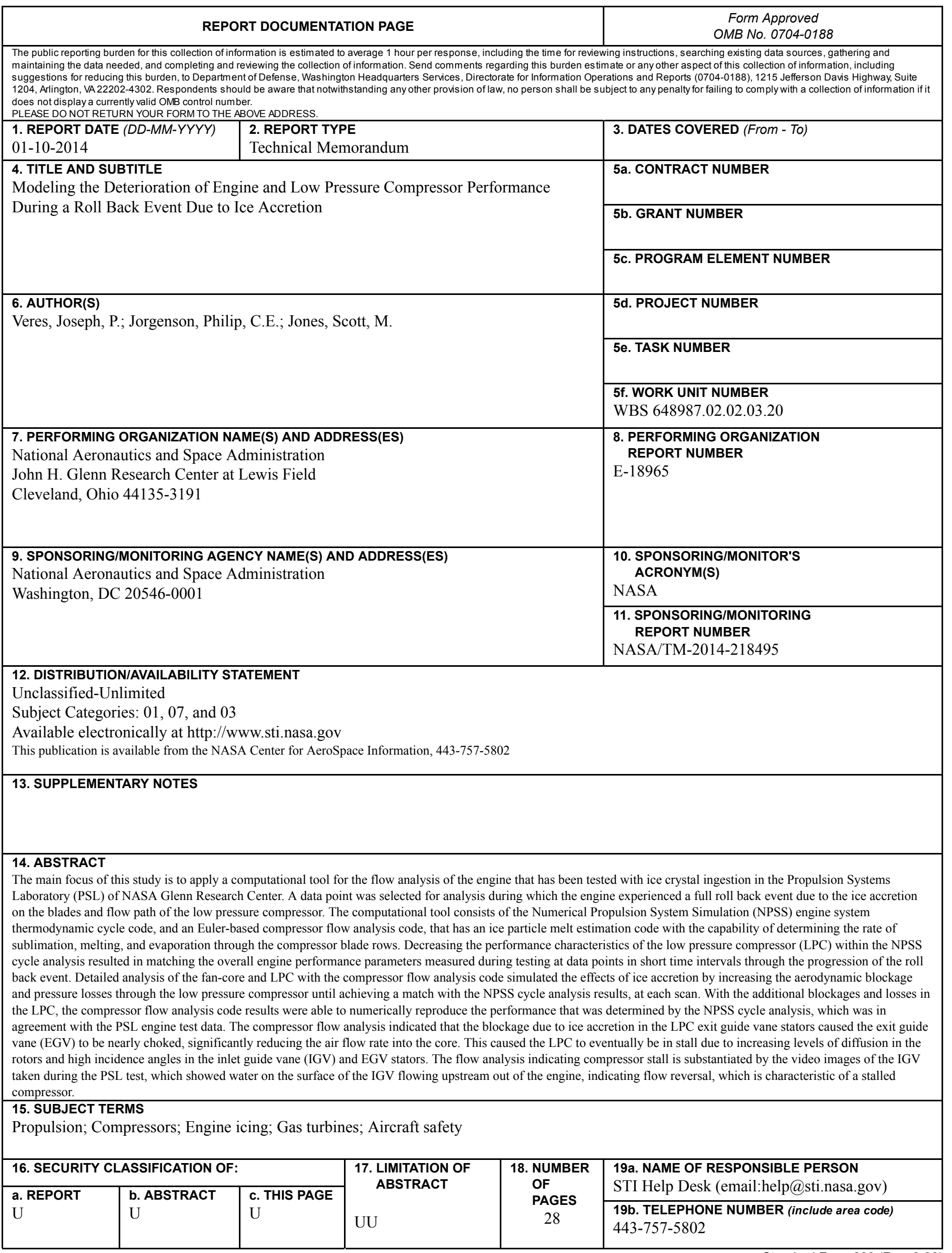



